Supplementary Information for:

\title{
Organism engineering for the bioproduction of the triaminotrinitrobenzene (TATB) precursor phloroglucinol (PG)
}

Adam Meyer $^{1 *}$, Ishtiaq Saaem ${ }^{1,2,7 *}$, Adam Silverman ${ }^{3 *}$, Vanessa Varaljay $^{4 *}$, Rebecca Mickol ${ }^{8}$, Steven Blum $^{6}$, Alexander Tobias $^{10}$, Nathan D. Schwalm III ${ }^{10}$, Wais Mojadedi ${ }^{11}$, Elizabeth Onderko ${ }^{9}$, Cassandra Bristol $^{2,7}$, Shangtao Liu ${ }^{1,2}$, Katelin Pratt ${ }^{2,7}$, Arturo Casini ${ }^{2,7}$, Raissa Eluere ${ }^{2,7}$, Felix Moser ${ }^{1}$, Carrie Drake ${ }^{12}$, Maneesh Gupta ${ }^{4}$, Nancy Kelley-Loughnane ${ }^{4}$, Julius Lucks ${ }^{3}$, Katherine Akingbade ${ }^{10}$, Matthew Lux ${ }^{6}$, Sarah Glaven $^{5}$, Wendy Crookes-Goodson ${ }^{4}$, Michael C. Jewett ${ }^{3}$, D. Benjamin Gordon ${ }^{1,2,7}$, and Christopher A. Voigt $^{1,2}$

1 Synthetic Biology Center, Department of Biological Engineering, Massachusetts Institute of Technology, Cambridge, MA USA

2 The Foundry, 75 Ames St., Cambridge MA USA

3 Center for Synthetic Biology, Department of Chemical and Biological Engineering, Northwestern University, Evanston, IL, USA.

4 Soft Matter Materials Branch, Materials and Manufacturing Directorate, Air Force Research Laboratory, Wright-Patterson AFB, Ohio, USA.

5 Center for Bio/Molecular Science and Engineering, Naval Research Laboratory, Washington, DC, USA.

6 US Army Combat Capabilities Development Command Chemical Biological Center. 8198 Blackhawk Rd, APG MD

7 Broad Institute of MIT and Harvard, Cambridge MA

8 American Society for Engineering Education, 1818 N Street NW Suite 600, Washington, DC 20036, USA

9 National Research Council, 500 Fifth Street NW, Washington, DC 20001, USA

10 US Army Research Laboratory, FCDD-RLS-EB, 2800 Powder Mill Road, Adelphi, MD 20783, USA

11 Oak Ridge Associate Universities, P.O. Box 117, MS-29, Oak Ridge, TN 37831-0117, USA

12 UES, Inc., 4401 Dayton-Xenia Rd, Dayton, Ohio, 45432, USA

*These authors contributed equally to this work, and are listed in alphabetical order. 


\section{Contents}

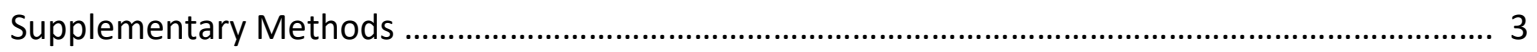

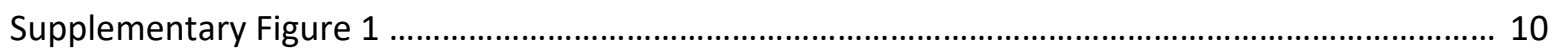

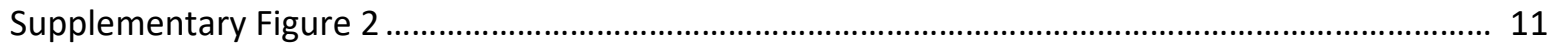

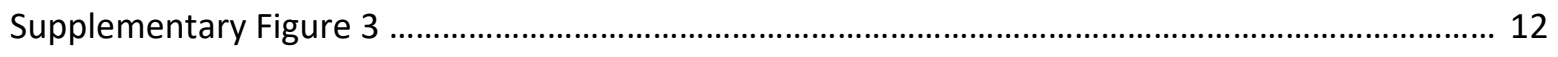

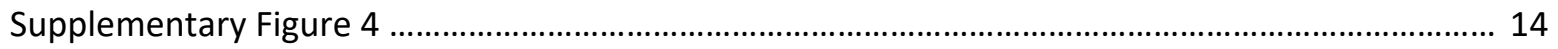

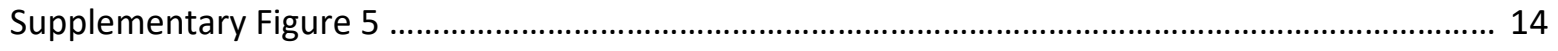

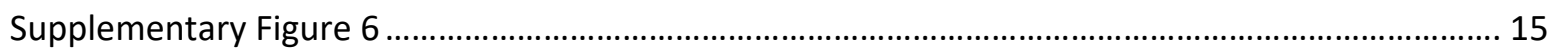

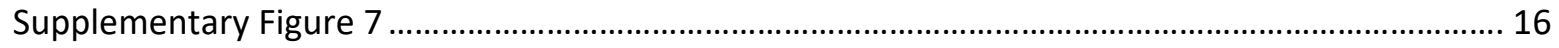

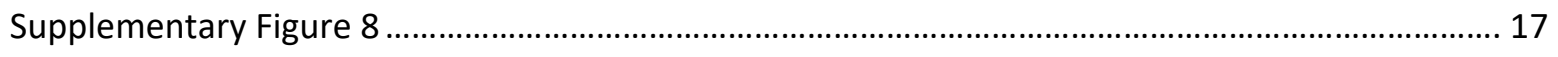

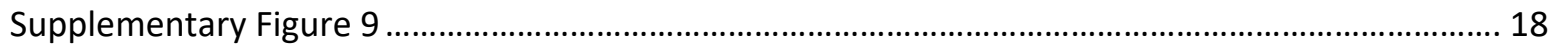

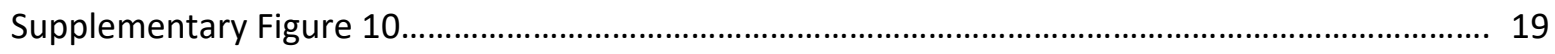

Supplementary Table 1: Primer table and PCR specifications ........................................................ 21

Supplementary Table 2: Shuttle plasmids used to express phID in Clostridium acetobutylicum ..... 22

Supplementary Table 3: Optimization of a cell-free DAPG-responsive promoter …........................23

Supplementary Table 3: Genetic part sequences ............................................................................. 24

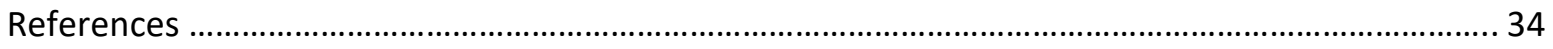




\section{Supplementary Methods}

Strains, plasmids, and media. Escherichia coli DH10B (Part \# C3019, C3020. New England Biolabs, Ipswich, MA - USA.) was used for all routine cloning and assays. All E. coli expression and sensor plasmids contain p15A origins of replication and kanamycin resistance. All phloroglucinol (phloroglucinol) conversion plasmids contain colE1 origins of replication and chloramphenicol, spectinomycin or kanamycin resistance. LB-Miller media (Part \# 244620. BD, Franklin Lakes, NJ - USA) was used for cytometry assays. 2xYT liquid media (BD, Franklin Lakes, NJ - USA), LB media and LB + 1.5\% agar (Part \# 244020. BD, Franklin Lakes, NJ - USA) plates were used for routine cloning and strain maintenance.

The protein sequence for the Pseudomonas Pf-5 phID gene was codon-optimized for $E$. coli, B. subtilis and Marinobacter. The protein sequence of the new variant $p h I D^{P 79}$ was codon-optimized for $E$. coli and Marinobacter. Cut sites were added and, subsequently, Golden Gate assembly methods were used to clone the genes into an expression plasmid for E. coli (pAC10, an in-house T7 controlled expression vector) and into a vector for Marinobacter (pBBR1MCS-2. Addgene. Cambridge, MA - USA). For Bacillus subtilis, phID was inserted into pHT01 (Mobitec GMBH - Germany), a commercial vector that allows for plasmid-based expression, and also into integrative plasmid pJAB980 that can integrate into the amyE starch utilization locus of the $B$. subtilis chromosome. Bsal-HF or other appropriate restriction endonucleases and T4 DNA ligase (Part \# R3535, M0202. New England Biolabs, Ipswich, MA - USA.) were used to cut DNA and assemble the plasmids ${ }^{1}$. Assembled plasmids were transformed into $E$. coli DH5 $\alpha$ (Part \# C2987. New England Biolabs, Ipswich, MA - USA.) cells using electroporation. Colonies were picked and grown in LB overnight at $37^{\circ} \mathrm{C}$ with requisite antibiotic selection. The plasmids were then extracted using the Qiagen QIAprep plasmid extraction kit (Part \# 27106. Qiagen, Hilden Germany) and sent to Quintara Biosciences (Boston) for verification by Sanger sequencing.

The cell-free sfGFP reporter plasmid pJBL7029 was constructed from pJBL7010 using overhang PCR and blunt-end ligation of the SfGFP insert. The phIF repressor plasmid pJBL7027 and the phIACB plasmid pJBL7028 were constructed using Gibson assembly.

E. coli-Clostridium shuttle vectors listed in Supplementary Table 2 for expression of PG synthase in E. coli and $C$. acetobutylicum were constructed from pMTL80000-series modular base vectors from CHAIN Biotech ${ }^{2}$. Construction of theophylline-inducible phID expression plasmid pAVT060 began with base vector backbone pMTL85141 (CHAIN Biotech, Marlow - UK) containing a ColE1 Gram-negative replication origin, a catP gene providing resistance to chloramphenicol (for E. coli cultivation) or thiamphenicol (for Clostridium cultivation), and CD0164 and Cpa fdx bidirectional terminators. DNA parts encoding a phID expression cassette comprising a thiolase promoter, theophylline riboswitch " $\mathrm{E}$ " ${ }^{3}$, and phID variant " $4 \mathrm{x}-2$ " ${ }^{4}$ codon-adapted for Clostridium acetobutylicum using Genome Compiler ${ }^{\circledast}$ software, were purchased from commercial DNA suppliers (Twist, Genscript) and were inserted into the multi-cloning site of pMTL85141 by a combination of NEBuilder ${ }^{\circledR}$ assembly (New England Biolabs) and standard restriction-ligation to generate pAVT060. Plasmids pAVT061, pAVT062, and pAVT063 were generated from pAVT060 by substituting the pIM13 Gram-positive origin with the pBP1, pCB102, or pCD6 origin, respectively, from other pMTL80000-series modular vectors by restriction-ligation (Ascl and Fsel). Plasmid pAVT080 was generated from pAVT060 by removing the riboswitch using NEBuilder ${ }^{\circledR}$ assembly. Plasmid pAVT089 was generated from pAVT060 by appending a 27-nucleotide sequence encoding the 9 -amino acid HA Tag (YPYDVPDYA) to $p h / D^{4 x-2}$ by NEBuilder ${ }^{\circledR}$ assembly. 
Linalool strain construction and expression. The truncated form of the yeast HMGR lacking the membrane-binding region (tHMGR) was overexpressed using a gal1 promomter, and ERG9 was placed under the repressible promoter MET3. We amplified the yeast promoter MET3 from CEN-PK strain and integrated it in front of the ERG9 gene (with a KanMX cassette) by homologous recombination. Additionally, we tried different versions of the linalool synthase gene. These included codon-optimized and native versions of the LIS gene from Lavandula angustifolia, as well as two truncated genes. These were trnc67McLIS, a truncated version of McLIS from Mentha citrata that has been previously shown to increase expression of linalool in yeast CEN.PK ${ }^{5}$ and an analogous truncated form of the gene from $L$. angustifolia in which the putative $\mathrm{N}$-terminal plastid targeting sequence has been removed based on sequence homology with McLIS. Fermentation was carried out in yeast expression media using noted markers, extracted using ethyl acetate and analyzed by GC-MS.

Pseudomonas isolate identification. Field studies were conducted and microbes were collected from aircraft using nylon swabs into 1X Phosphate Buffered Saline (PBS) (Part \# 223142. BD, Franklin Lakes, NJ - USA) ${ }^{6}$. Pseudomonas isolates were identified using $16 \mathrm{~S}$ rRNA gene sequencing from isolates grown on Tryptic Soy Agar (TSA) (Part \# 236940. BD, Franklin Lakes, NJ - USA) plates at $27^{\circ} \mathrm{C}$ for 3 days. Approximately $10 \mathrm{mg}$ of biomass was used for DNA extractions with the ZR Fungal/Bacterial DNA MicroPrep ${ }^{\text {TM }}$ Kit (Part \# D6007. Zymo Research, Irvine, CA - USA) following the recommended protocol. The extracted DNA was archived, used for phID screening by PCR as described below, and quantified using a NanoDrop microvolume spectrophotometer (Thermo Fisher Scientific, Waltham, MA - USA).

Screening of a Pseudomonas library for phID sequences by PCR. For each Pseudomonas isolate, a near full-length portion of the 16S rRNA gene was amplified. The $25-\mu$ reactions contained $1 \mathrm{X}$ Green GoTaq ${ }^{\circledR}$

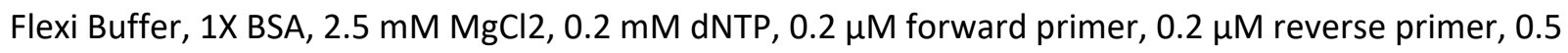
units of GoTaq ${ }^{\circledR}$ Flexi DNA Polymerase (Part \# M829, Promega, Madison, WI - USA), and 20 ng of DNA. PCR products were purified using the QIAquick PCR purification kit (Qiagen, Hilden - Germany) and concentrations were determined with a NanoDrop. Sanger sequencing was performed and the ribosomal sequences from 112 Pseudomonas isolates were aligned with one another and differentiated into 9 clusters at $99 \%$ sequence similarity.

In order to build a phID signature for primer designs, the Pseudomonas protegens Pf-5 PhID amino acid sequence was used as a BLASTP query search to interrogate Pseudomonas sequences present in the $\mathrm{NCBI}$ "nr" protein database for putative PhID sequences. From the NBCl hits, PhID orthologs were identified using reciprocal BLASTP against the $P$. protegens Pf-5 genome to verify PhID as the top hit. PhID orthologs were further verified and clades were delineated by constructing a PhID amino acid tree with MUSCLE alignment and Neighbor-Joining tree methodology using the Jukes-Cantor genetic distance model and bootstrapping with 100 replicates.

In silico primer design was performed with both amino acid and nucleotide sequence alignments to identify conserved regions for phID universal primer optimization based on existing phID primers. Based on the PhID amino acid tree, 6 clade-specific primer sets (clades A, B, C, D, E, and F) were designed de novo based on nucleotide alignments within each of these clades. The clade-specific primers were designed without degeneracies and to bind at the start and stop sites, capturing the entirety of the phID gene Open Reading Frames (ORFs). In a first round of PCR-based phID gene screening across the 9 clusters of Pseudomonas isolates, 52 of the 112 isolates were tested. Briefly, the $25-\mu$ l reactions 
contained 1X Green Go Flexi Taq buffer, 1X BSA, $1 \mathrm{mM}$ dNTP, $0.8 \mu \mathrm{M}$ forward primer, $0.8 \mu \mathrm{M}$ reverse primer, 0.5 units of GoTaq ${ }^{\circledast}$ Flexi DNA Polymerase (Part \# M829. Promega, Madison, WI - USA), and 20 ng of DNA. Reaction conditions were also tested with Phusion high-fidelity DNA polymerase (Part \# M0530. New England Biolabs, Ipswich, MA - USA.) with the provided Phusion HF buffer. In a second round of PCR screening, phID clade-specific primers were used to screen for phID hits. Ultimately, two $P$. aeruginosa phID sequences were found that had only 71\% identity with the Pf-5 phID sequence and thus represent new enzyme variants. Both sequences were identical to each other and, as a result, the variant named P79 was expressed and presented.

PhID expression in E. coli to produce PG. The verified Pf-5 phID gene in pAC10 was transformed using the heat shock method into BL21(DE3) (Part \# C2527. New England Biolabs, Ipswich, MA - USA.) for expression. Three colonies were picked for screening and to determine the best growth conditions via LCMS. The colony with the highest PG production was selected to run in triplicate along with strains containing an empty vector. Starter cultures were grown overnight at $37^{\circ} \mathrm{C}$ in $20 \mathrm{ml}$ of TB medium (Part \# 243820. BD, Franklin Lakes, NJ - USA) supplemented with kanamycin. Seven milliliters of starter culture was used to inoculate $200 \mathrm{ml}$ of TB-Kan for expansion growth. The expansion growth was allowed to grow at $37^{\circ} \mathrm{C}$ shaking at $250 \mathrm{rpm}$ until an $\mathrm{OD}_{600 \mathrm{~nm}}$ of $0.8-1.2$ was reached. Cells were then centrifuged in 50-ml aliquots and resuspended in Ez Rich medium (Part \# M2105. Teknova, Hollister, CA - USA) containing 0.5 mM IPTG (Part \# 1425. Teknova, Hollister, CA - USA) and allowed to grow for noted times, shaking at $250 \mathrm{rpm}$ at a temperature of $30^{\circ} \mathrm{C}$.

PhID expression in Bacillus subtilis to produce PG. Plasmid pHT01-phID containing the Pf5 phID codonoptimized for $B$. subtilis was transformed into $B$. subtilis Marburg 168 by mixing $0.2 \mathrm{~mL}$ of competent cells with 500 ng of plasmid DNA prepared from a recA+ strain of $E$. coli. This mixture was shaken at 37 ${ }^{\circ} \mathrm{C}$ for 1 hour at $250 \mathrm{rpm}$. One milliliter of LB was then added. After another hour of shaking, the transformation mixture was plated. Integrative plasmid pJAB980-phID was transformed into $B$. subtilis $\mathrm{XPORT}^{7}$ strains by electroporation. Cells were grown overnight in 2XYT medium, diluted 100 -fold and grown to an $\mathrm{OD}_{600 \mathrm{~nm}}$ of 0.2 . The culture was then supplemented with $1 \%$ DL-threonine, $2 \%$ glycine, $0.1 \%$ tryptophan and $0.03 \%$ Tween 80 and shaken for $1 \mathrm{~h}$. Cells were then centrifuged at $5000 \times g$ for $10 \mathrm{~min}$ at $4{ }^{\circ} \mathrm{C}$ and washed twice with electroporation buffer. After washing, cells were resuspended in electroporation buffer and $100 \mu \mathrm{l}$ of cells were added to an ice-cold $2 \mathrm{~mm}$ cuvette along with $2 \mu \mathrm{l}$ of plasmid DNA $(25 \mathrm{ng} / \mu \mathrm{l})$. Electroporation was performed with a single $2.1 \mathrm{kV} / \mathrm{cm}$ pulse (Gene Pulser; BioRad) resistance of $200 \Omega$ and $25 \mu \mathrm{F}$ capacitance. One milliliter of 2 xYT broth containing $0.5 \mathrm{M}$ sorbitol and $0.38 \mathrm{M}$ mannitol was immediately added, and the electroporated cells were incubated at $37{ }^{\circ} \mathrm{C}$ for 3 $\mathrm{h}$ before being spread onto $2 \mathrm{XYT}$ plates. Three clones of each type of transformed $B$. subtilis were grown for 24 and 48 hours in 2XYT media.

PhID expression in Marinobacter to produce PG. PG production by Marinobacter atlanticus CP1 was tested in two different media: rich medium (BB) and minimal medium (artificial seawater; ASW), both supplemented with $50 \mu \mathrm{g} / \mathrm{mL}$ kanamycin (designated Kan50). BB medium contains, per liter: $18.7 \mathrm{~g}$ marine broth (Part \# 279110. BD, Franklin Lakes, NJ - USA), 5 g tryptone (Part \# 97063. VWR, Radnor, PA - USA), $5 \mathrm{~g} \mathrm{NaCl}$ (Part \# BDH9286. VWR, Radnor, PA - USA), and $2.5 \mathrm{~g}$ yeast extract (Part \# IC10330380. VWR, Radnor, PA - USA). For typical minimal medium experiments for $M$. atlanticus, artificial seawater (ASW) medium consists of, per liter: $27.5 \mathrm{~g} \mathrm{NaCl}$ (Part \# 470302. VWR, Radnor, PA - USA), $3.8 \mathrm{~g}$ $\mathrm{MgCl}_{2} \bullet 6 \mathrm{H} 2 \mathrm{O}$ (Part \# AAJ62411. VWR, Radnor, PA - USA), $6.78 \mathrm{~g} \mathrm{MgSO}_{4} \bullet 7 \mathrm{H}_{2} \mathrm{O}$ (Part \# 95034. VWR, Radnor, PA - USA), 0.72 g KCl (Part \# 10013. VWR, Radnor, PA - USA), $0.62 \mathrm{~g} \mathrm{NaHCO}_{3}$ (Part \# 200002. 
VWR, Radnor, PA - USA), $0.05 \mathrm{~g} \mathrm{CaCl}_{2} \bullet 2 \mathrm{H}_{2} \mathrm{O}$ (Part \# C1086. VWR, Radnor, PA - USA), $1 \mathrm{~g} \mathrm{NH}{ }_{4} \mathrm{Cl}$ (Part \# 130480. VWR, Radnor, PA - USA), $0.05 \mathrm{~g} \mathrm{~K}_{2} \mathrm{HPO}_{4}$ (Part \# BJP3786. VWR, Radnor, PA - USA), and $1 \mathrm{~mL}$ Wolfe's trace mineral solution (Part \# MSPP-MDTMS. VWR, Radnor, PA - USA), supplemented with $7 \mathrm{~g}$ sodium succinate dibasic hexahydrate (Part \# 89230. VWR, Radnor, PA - USA) added as a carbon source. The ASW medium was brought to a final $\mathrm{pH}$ of 6.5-6.8 after autoclaving with $\mathrm{CO}_{2}$. In the experiments conducted here, the ASW medium was amended for low-nitrogen conditions, utilizing only $0.1 \mathrm{~g} \mathrm{NH}_{4} \mathrm{Cl}$ (as compared to $1 \mathrm{~g} / \mathrm{L} \mathrm{NH}_{4} \mathrm{Cl}$ ) in order to promote the wax ester pathway.

Marinobacter atlanticus CP1, carrying plasmid pBBR1MCS-2 with the phID gene (CP1::phID) was shaken in $20 \mathrm{~mL}$ rich (BB-Kan50) or minimal (ASW-Kan50) medium at $30^{\circ} \mathrm{C}$ and $230 \mathrm{rpm}$ overnight ( 24 hours). M. atlanticus $\triangle$ farA $\triangle a c r B$ carrying plasmid pBBR1MCS-2 with the phID gene ( $\triangle$ farA $\triangle a c r B:: p h I D)$ was shaken in $20 \mathrm{~mL}$ rich (BB-Kan50) or minimal (ASW-Kan50) medium at $30^{\circ} \mathrm{C}$ and $230 \mathrm{rpm}$ overnight ( 24 hours). From each of these $20-\mathrm{mL}$ cultures, $10 \mathrm{~mL}$ was used to inoculate $400-\mathrm{mL}$ batch cultures: CP1::phID BB-Kan50, CP1::phID ASW-Kan50, farA $\Delta a c r B:: p h I D$ BB-Kan50, CP1, farA $\triangle a c r B:: p h I D ~ A S W-$ Kan50. The batch cultures were shaken at $30^{\circ} \mathrm{C}$ and $230 \mathrm{rpm}$ for 100 hours. At 48 hours, two $35-\mathrm{mL}$ aliquots from each batch culture were transferred to separate $50-\mathrm{mL}$ centrifuge tubes. An additional 5 $\mathrm{mL}$ was removed from each batch culture for $\mathrm{pH}$ and optical density measurements.

PhID expression in Clostridium to produce PG. CpG-methylated plasmids were transformed into $C$. acetobutylicum by electroporation ( $4 \mathrm{~mm}$ gap, $2 \mathrm{kV}$ exponential decay, $25 \mu \mathrm{F}$, infinite resistance) of fresh cultures grown to $\mathrm{OD}_{600 \mathrm{~nm}} 1.1-1.5$, then washed 3 times with ice-cold transformation buffer ( $275 \mathrm{mM}$ sucrose, $5 \mathrm{mM}$ sodium phosphate pH 7.4). Clostridial Growth Medium (CGM) ${ }^{8}$ agar plates were supplemented with $5 \mathrm{~g} / \mathrm{L}$ glucose and, for plasmid-harboring strains, $15 \mu \mathrm{g} / \mathrm{mL}$ thiamphenicol. Liquid cultures were grown in Reinforced Clostridial Medium (RCM) ${ }^{9}$ supplemented with $20 \mathrm{~g} / \mathrm{L}$ glucose and, for plasmid-harboring strains, $30 \mu \mathrm{g} / \mathrm{mL}$ thiamphenicol. Clostridium was manipulated and cultivated in an anaerobic chamber (Coy Laboratory Products, Grass Lake, MI - USA) equipped with an incubator, in an atmosphere of $1.0-2.5 \% \mathrm{H} 2 / 5 \% \mathrm{CO}_{2} /$ balance $\mathrm{N}_{2}$. For attempts at clostridial PG biosynthesis, $45-\mathrm{mL}$ Clostridium cultures were grown in static $50-\mathrm{mL}$ tubes starting from a $0.5-\mathrm{mL}$ liquid culture inoculum or loop of cells from a plate. The incubator temperature was set to $37^{\circ} \mathrm{C}$ for the first $\sim 7 \mathrm{hr}$. and was then decreased to $28^{\circ} \mathrm{C}$. Riboswitch-containing strains were induced with a final concentration of $2 \mathrm{mM}$ theophylline added from a $200 \mathrm{mM}$ stock solution in DMSO. Uninduced controls were provided an equivalent volume of DMSO. Cultures were harvested after $48-80$ hours, then analyzed by HPLC.

Determination of plasmid copy number in Clostridium by qPCR. Plasmid copy number relative to genomic DNA was determined for $C$. acetobutylicum strains harboring plasmids with different replication origins by quantitative PCR (qPCR) (Supplementary Figure 8). A Quant Studio 3 instrument was used with PowerUp SYBR Green Master Mix (Applied Biosystems). Genomic and plasmid DNA were prepared from C. acetobutylicum using the E.Z.N.A. ${ }^{\circledR}$ Bacterial DNA Kit (Omega Bio-Tek). Relative threshold cycle $\left(C_{t}\right)$ values obtained from primers targeting the plasmid-borne catP gene were normalized to $C_{t}$ values from primers targeting the CA_C0905 chromosomal gene (dehydrogenase) to provide estimates of plasmid copy number. Primers targeting the CA_P0098 gene (alpha-amylase) on the $C$. acetobutylicum megaplasmid were used as a control.

Western blot of PhID produced by recombinant C. acetobutylicum. Lysates of Clostridium cultures harboring plasmid pAVT089 encoding HA-tagged PhID were generated by combining cells, protease inhibitor cocktail (Part \# P8849. Sigma-Aldrich, St. Louis, MO - USA), and $0.1 \mathrm{~mm}$ silica beads (Lysing 
Matrix B. MP Biomedicals, Irvine, CA - USA) followed by agitation with a Mini-G ${ }^{\circledR}$ cell lyser $(2 \times 75 \mathrm{sec}$., Spex ${ }^{\circledR}$ Sample Prep). Protein content was estimated by the absorbance at $280 \mathrm{~nm}$ with a DeNovix DS-11 spectrophotometer. Approximately $100 \mu \mathrm{g}$ of lysate (protein basis) was subjected to SDS-PAGE in an Any-kDTM Mini-PROTEAN ${ }^{\circledR}$ TGXTM gradient gel (Bio-Rad) along with a Precision Plus Kaleidoscope protein standard (Bio-Rad). Separated proteins were transferred to a PVDF membrane with a TransBlot $^{\circledR}$ TurboTM Transfer System (Bio-Rad). After blocking the membrane with fat-free milk solution in PBS, it was incubated with anti-HA primary antibody $(0.25 \mu \mathrm{L} / \mathrm{mL}$, Part \# H6908. Sigma-Aldrich, St. Louis, MO - USA) overnight with refrigeration. After PBS washing, goat anti-rabbit secondary antibody-HRP conjugate was applied to the membrane $(0.2 \mu \mathrm{L} / \mathrm{mL}$, Bio-Rad 1706515) and incubated with shaking for 1 $\mathrm{hr}$. The membrane was washed with PBS $3 \times 15 \mathrm{~min}$. before addition of $1 \mathrm{~mL}$ of 2-fold diluted SuperSignal ${ }^{\mathrm{TM}}$ West Femto Maximum Sensitivity chemiluminescent substrate (Thermo Scientific 34095) and imaging with a VersaDocTM Molecular Imager (Bio-Rad).

PhID enzyme assays. Lysates of $E$. coli or Clostridium cultures generated as described above were assayed for phID enzyme activity essentially as described by Zha et al ${ }^{10}$. Lysates were incubated at $25^{\circ} \mathrm{C}$ with shaking with 400 or $40 \mu \mathrm{M}$ of malonyl coenzyme A (Part \# 16455. Cayman Chemical, Ann Arbor, MI - USA) for 24 hours, then analyzed by HPLC.

Extraction and LCMS detection of PG. Expression cultures were centrifuged at $7500 \times g$ for 30 minutes. Next, the supernatant was poured into a separate $50-\mathrm{mL}$ centrifuge tube. Additional supernatant was removed from the pellets using a 1- $\mathrm{mL}$ pipette. The pellets were weighed against an empty $50-\mathrm{mL}$ tube. The tubes containing the pellets and the tubes containing the supernatants were stored at $-80{ }^{\circ} \mathrm{C}$ for 3 days. At 100 hours, two 35-mL aliquots were removed from each batch culture and processed similarly to the 48-h aliquots. Supernatant was mixed with methanol (Part \# 67-56-1. VWR, Radnor, PA - USA) at a 1:1 ratio. The mixture was centrifuged at $15000 \times g$ for 30 minutes and $100 \mu \mathrm{L}$ was injected into an HPLC-MS (Agilent 6130 Quadrupole) with a reverse phase column and a mobile phase consisting of water with $0.1 \%$ formic acid (Part \# JT9834. VWR, Radnor, PA - USA) for 5 minutes.

Flow cytometry analysis. Characterization of the PG-sensing cells was accomplished with a BD LSR Fortessa flow cytometer with HTS attachment (BD, Franklin Lakes, NJ - USA). Cells diluted in PBS + kanamycin were introduced at a rate of $0.5 \mu \mathrm{l} / \mathrm{s}$. The events were gated by forward scatter height (midlog: 1,000-10,000; stationary: 500-5000) and side scatter area (mid-log: 1,000-10,000; stationary: 500$5,000)$ to reduce false events. After gating, thousands of events were used for analysis. For each sample, the median YFP fluorescence was calculated. All output values are reported in terms of relative promoter units (RPU). For a given promoter measurement, E. coli $\mathrm{DH} 10 \mathrm{~B}$ is transformed with the relevant plasmid(s). The strain is then assayed by flow cytometry alongside $E$. coli DH10B containing the RPU standard plasmid as well as an autofluorescence control. Adjusted median fluorescence values are determined by subtracting the median of the autofluorescence control from each sample's median fluorescence, including that of the RPU standard. Sensor cell output RPU values are then computed by dividing adjusted median fluorescence values by the adjusted median of the RPU standard.

PhIF response function measurements. Single colonies were inoculated into $1 \mathrm{~mL} \mathrm{LB}+$ antibiotics in 2-mL 96-deepwell plates (USA Scientific, Orlando, FL - USA) sealed with an AeraSeal film (Excel Scientific, Victorville, CA - USA) and shaken at $37^{\circ} \mathrm{C}, 900 \mathrm{rpm}$ overnight in a Multitron Pro shaker incubator (INFORS HT, Bottmingen, Switzerland). The overnight growths were diluted 1:200 into $1 \mathrm{ml} \mathrm{LB} \mathrm{+}$ antibiotics in 2-mL 96-deepwell plates + AeraSeal film and grown at $37^{\circ} \mathrm{C}, 900 \mathrm{rpm}$. After 2 hours, the 
cultures were diluted 1:500 into prewarmed LB + antibiotics + inducer where necessary in 2-mL 96deepwell plates + AeraSeal film. For mid-log phase or stationary phase measurements, plates were grown at $37^{\circ} \mathrm{C}, 900 \mathrm{rpm}$ for 5 hours or 20 hours, respectively. After growth, for mid-log phase, $20 \mu \mathrm{L}$ of culture sample was diluted into $180 \mu \mathrm{L}$ PBS $+200 \mu \mathrm{g} / \mathrm{mL}$ kanamycin to inhibit translation. For stationary phase, $2 \mu \mathrm{L}$ of culture sample was diluted into $198 \mu \mathrm{L}$ PBS $+200 \mu \mathrm{g} / \mathrm{mL}$ kanamycin to inhibit translation.

Fitting of Hill equation to the PhIF response function. To parameterize the response function, error minimization was performed using the Solver function in Excel software (Microsoft, Redmond, WA USA). The Hill equation was entered with $y_{\min }, y_{\max }, K$, and $n$ as tunable parameters, $x$ (inducer concentration) as the independent variable and $y$ as the output. For each $x$, the error between the measured output RPU value and the $y$ value of the function was determined. The total error was determined by summing the normalized square of the error ([y-measured RPU value $]^{2} / y$ ) for each $x$. The Solver function minimized the total error by tuning $y_{\min }, y_{\max }, K$, and $n$.

Cell-free extract preparation. Cell-free extract was prepared from a BL21 (DE3) LacZ-deficient strain. A 1 $\mathrm{L}$ culture of $2 \mathrm{XYT}+\mathrm{P}$ medium was inoculated from an overnight culture of the host strain and grown at $37^{\circ} \mathrm{C}$. T7 RNAP synthesis was induced in both the phIACB-enriched and plasmid-free strains by addition of $500 \mu \mathrm{M}$ IPTG at an $\mathrm{OD}_{600 \mathrm{~nm}}$ of 0.5 . The cells were harvested at $O D_{600 \mathrm{~nm}} 3.0$ after about 3.5 hours by centrifugation at 5,000 $\mathrm{g}$. Due to poor growth of the phIACB-overexpressing strain, it was instead harvested at $\mathrm{OD}_{600 \mathrm{~nm}} 2.0$ after approximately five hours of growth. The cell pellets were washed three times, resuspended in $1 \mathrm{~mL}$ buffer/g cells, and then lysed by sonication. The lysate was centrifuged for 10 minutes at $12,000 \times g$, subjected to an 80 -minute ribosomal runoff reaction, a second centrifugation at $12,000 \times g$, a 3-hour dialysis with no buffer exchanges through a $10 \mathrm{~K} \mathrm{MWCO} \mathrm{membrane,} \mathrm{and} \mathrm{one} \mathrm{final}$ centrifugation at $12,000 \times \mathrm{g}$. The final processed S12 extract was snap-frozen with liquid nitrogen and stored at $-80^{\circ} \mathrm{C}$.

Selection of hybrid promoter for cell-free expression. Synthetic promoters were designed by inserting the phlO operator into PTac, PT7, and PJ23119 promoters (Supplementary Table 3). The J23119-phIO promoter showed the highest ON state in the absence of the repressor (extract batch 1), which was around 10X higher expression than the Tac promoter used for the cellular sensor. Moreover, it was still induced by saturating concentrations $(200 \mu \mathrm{M})$ of DAPG (extract batch 2$)$. Each experiment consisted of $10 \mathrm{nM}$ sfGFP reporter plasmid and $1 \mathrm{nM}$ phIF expression plasmid, co-expressed in a $10 \mu \mathrm{L}$ reaction for eight hours. For expression from the T7 promoter, purified T7 RNA polymerase $(0.10 \mathrm{mg} / \mathrm{mL})$ was also supplemented exogenously to the reaction

Cell-Free Gene Expression Reaction. Cell-free gene expression reactions were assembled by mixing reaction buffer (composed of nucleotides, salts, cofactors, energy substrate, and amino acids) with extract ( $30 \% \mathrm{v} / \mathrm{v})$, plasmids, and PG or DAPG inducer ${ }^{11}$. Plasmids were prepared using the Qiagen Midiprep Kit (Qiagen, Hilden - Germany) and supplemented at a final concentration of $20 \mathrm{nM}$ for the phlO-sfGFP reporter plasmid (pADS094) and $10 \mathrm{nM}$ for the T7-phlF transcription factor repressor plasmid (pADS088). For experiments performed in tubes, cell-free reactions were assembled in triplicate and pipetted into a sealed 384 well-plate (Part \# 3712. Corning, Corning, NY - USA) where sfGFP fluorescence (emission/excitation: $485 / 520 \mathrm{~nm}$ ) was measured every five minutes on a BioTek Synergy $\mathrm{H} 1 \mathrm{~m}$ plate reader for four hours at $30^{\circ} \mathrm{C}$. Fluorescence values were correlated to equivalents of fluorescein isothiocyanate (FITC) using a previously-developed standard. For the experiments on paper, wax wells were printed onto Whatman 1 CHR chromatography paper (Part \# 3001-861. VWR, Radnor, 
PA - USA) using a Xerox Phaser 8580 printer. The printed paper ticket was baked at $125-135{ }^{\circ} \mathrm{C}$ for 5 minutes to allow the wax to penetrate the paper matrix and create a sealed well. After baking, the ticket was placed in a small petri dish containing $4 \mathrm{~mL}$ of blocking solution ( $5 \% \mathrm{BSA}$ in $\mathrm{diH}_{2} \mathrm{O}$ ) and placed on a

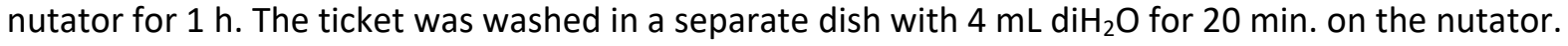
After washing, the ticket was allowed to air-dry in a fume hood. A plastic jar (Part \# 29258. Qosmedix, Ronkonkoma, NY - USA) housed the paper ticket during incubation to prevent drying. The jar bottom is concave, which ensured the ticket wells did not touch a surface and lose fluid by wicking. The corners of the ticket were nicked to allow for a more stable fit within the round jar. The ticket was placed in the jar and $3 \mu \mathrm{L}$ of each reaction species was pipetted from $25-\mu \mathrm{L}$ master mixes onto the wells in triplicate. Each reaction contained a mixture of phIACB-enriched lysate and plasmid-free lysate in a 10:90 ratio. Reactions were supplemented with $100 \mu \mathrm{g} / \mathrm{mL}$ T7 RNA polymerase and 2 units of RNAse inhibitor (New England Biolabs, Ipswich, MA - USA). Experimental ON (200 $\mu \mathrm{L} P \mathrm{PG})$ and OFF (0 $\mu \mathrm{L} P \mathrm{PG})$ reactions contained either (i) $20 \mathrm{nM}$ reporter plasmid and $10 \mathrm{nM}$ repressor plasmid, or (ii) $10 \mathrm{nM}$ reporter plasmid and $5 \mathrm{nM}$ repressor plasmid ( $\mathrm{pADS088}$ ). An equal volume of $\mathrm{diH}_{2} \mathrm{O}$ replaced absent constituents in the negative control (no DNA) reaction. The jar housing the spotted ticket and the remaining reaction master mix tubes were placed in a $-80^{\circ} \mathrm{C}$ freezer for $10 \mathrm{~min}$., then transferred to a lyophilizer (VirTis AdVantage. SP Scientific, Warminster, PA - USA). The ticket and the tubes were lyophilized for $18 \mathrm{~h}$. After lyophilization, each well of the ticket was rehydrated with $3 \mu \mathrm{L}$ of either $200 \mu \mathrm{L} \mathrm{PG} \mathrm{in} \mathrm{diH}_{2} \mathrm{O}(\mathrm{ON}$ and no-DNA conditions) or pure $\mathrm{diH}_{2} \mathrm{O}$ (OFF). Each tube was rehydrated with $15 \mu \mathrm{L}$ of rehydration solution in the same manner. To prevent drying of the rehydrated ticket, $100 \mu \mathrm{L}$ of $\mathrm{diH}_{2} \mathrm{O}$ was pipetted into the concave space at the bottom of the jar. The jar and tubes were capped and placed in the incubator at $30^{\circ} \mathrm{C}$ for 8 hours, with images captured at 5 min intervals (EOS Rebel T3. Canon, Ōta, Tokyo - Japan). 


\section{Supplementary Figure 1}

A

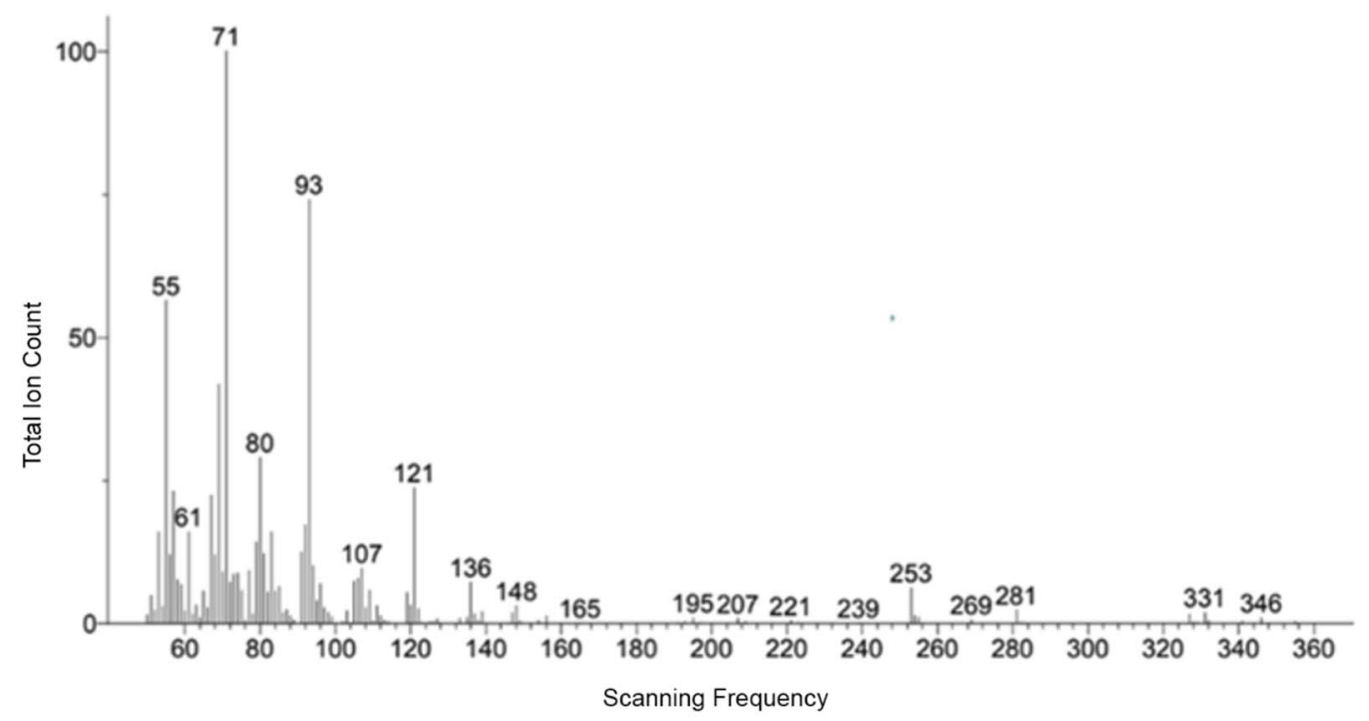

B

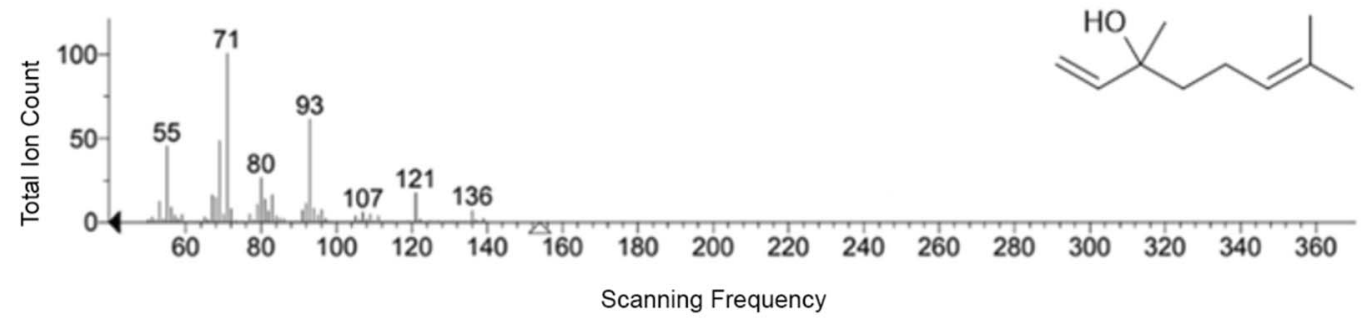

Production of linalool in S. cerevisiae. (A) Fermentation results from a linalool-expressing yeast strain via GC-MS, showing average total ion count between 7.991 to $8.044 \mathrm{~min}$. By performing a library search using the Agilent software, the spectrum was assigned to be linalool. Yeast (CEN.OK) was modified with a MET3 promoter to knock down ERG9 expression along with insertion of a KanMX selectable marker. Two plasmids (Ura and His) were inserted that carried the tHMGR and LIS genes under galactose inducible promoters. After fermentation using yeast expression media, extraction was performed using ethyl acetate prior to being analyzed on a GC-MS. (B) GC-MS spectrum for linalool standard from reference library. 


\section{Supplementary Figure 2}

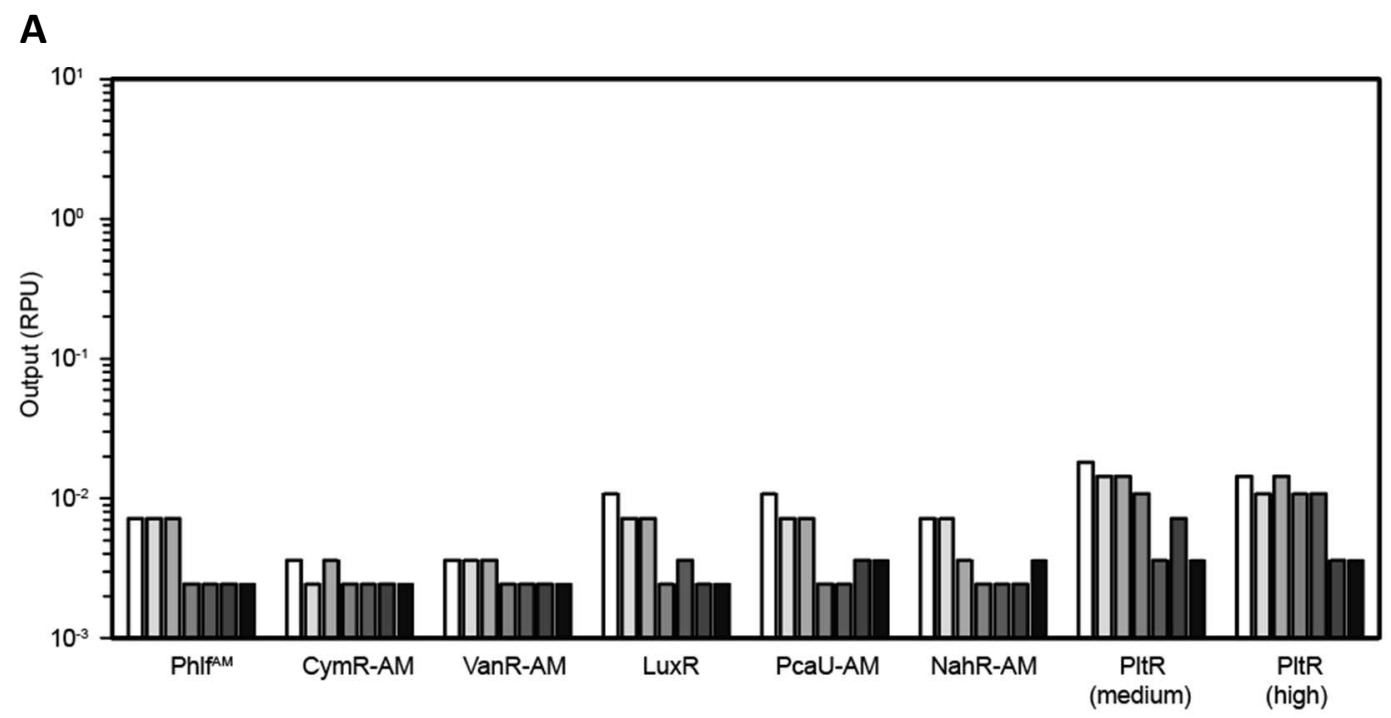

B

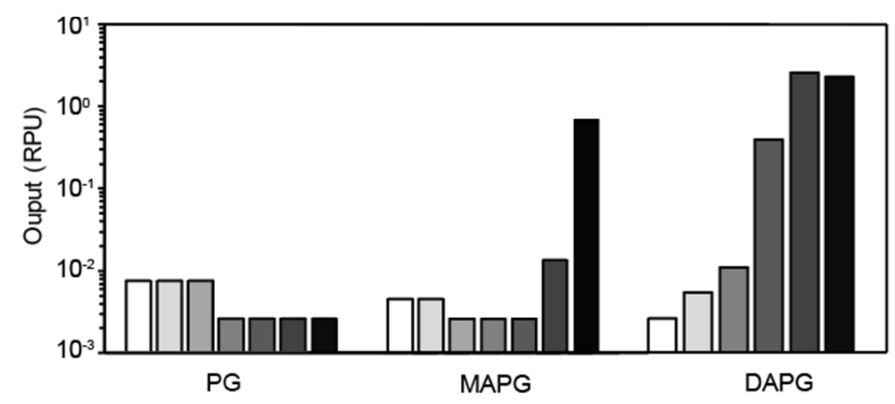

Screening of sensors for response to PG. (A) Responses to PG of several naturally-occurring sensors that respond to molecules with similar size and chemical composition to PG, namely PhIF ${ }^{A M}$, two 2,4diacetylphloroglucinol (DAPG) sensors; CymR ${ }^{\mathrm{AM}}$, a cuminic acid (Cuma) sensor; VanR ${ }^{\mathrm{AM}}$, a vanillic acid (Van) sensor, LuxR, a 3-oxohexanoyl-homoserine lactone (306) sensor; PcaU AM, a 3,4-dihydroxybenzoic acid (DHBA) sensor; NahR ${ }^{\text {AM }}$, a salicylate (Sal) sensor; and PItR, a 2,4-dichlorobenzene-1,3,5-triol (PGCl) sensor. Each sensor was tested using a fluorescent reporter system with the following concentrations of PG: $0 \mathrm{nM}, 3 \mathrm{nM}, 24 \mathrm{nM}, 195 \mathrm{nM}, 1.5 \mu \mathrm{M}, 12.5 \mu \mathrm{M}, 100 \mu \mathrm{M}$. (B) PhlF ${ }^{\mathrm{AM}}$ was tested for sensing PG, monoacetylpholoroglucinol (MAPG) and 2,4-diacetylphloroglucinol (DAPG). The following concentrations of each ligand were utilized: $0 \mathrm{nM}, 3 \mathrm{nM}, 24 \mathrm{nM}, 195 \mathrm{nM}, 1.5 \mu \mathrm{M}, 12.5 \mu \mathrm{M}$ and $100 \mu \mathrm{M}$. 


\section{Supplementary Figure 3}

A

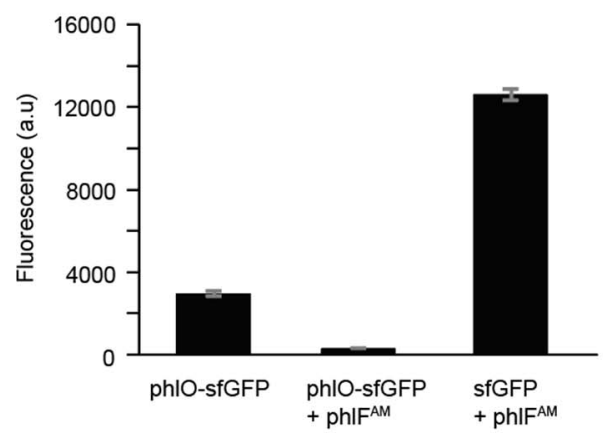

C

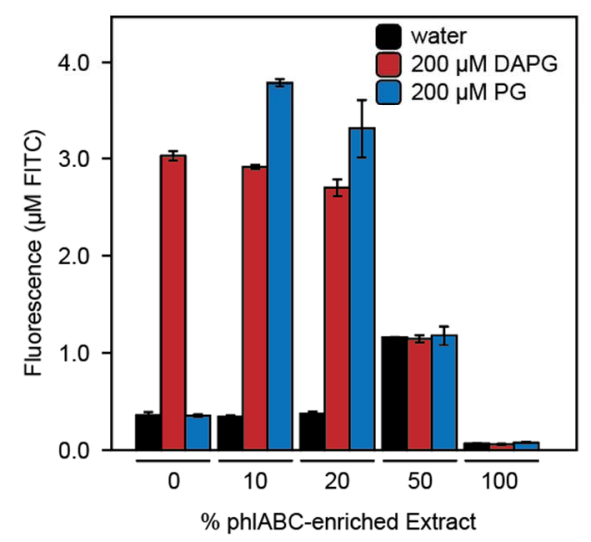

B

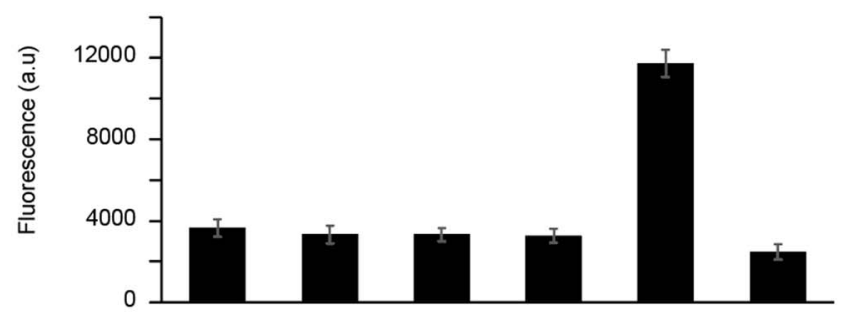

\begin{tabular}{|c|c|c|c|c|c|c|}
\hline Reporter Plasmid (nM) & 10 & 10 & 10 & 10 & 10 & 10 \\
\hline Repressor Plasmid (nM) & 0 & 2 & 2 & 2 & 2 & 2 \\
\hline phIABC Plasmid (nM) & 5 & 5 & 5 & 5 & 0 & 0 \\
\hline DAPG $(\mu \mathrm{M})$ & 0 & 0 & 5 & 0 & 5 & 0 \\
\hline PG $(\mu \mathrm{M})$ & 0 & 0 & 0 & 5 & 0 & 5 \\
\hline
\end{tabular}

D

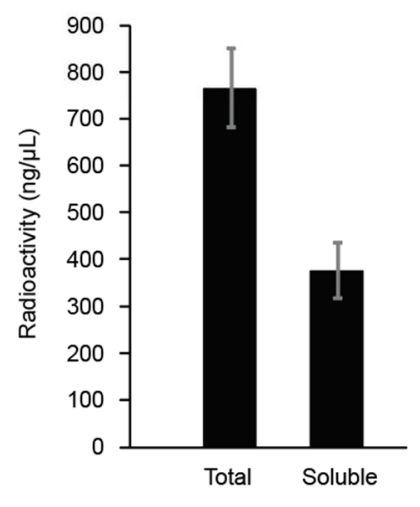

Cell-free sensor development. (A) Signal observed from constitutively-expressed T7-driven sfGFP when under control of a PhIF variant, PhIF ${ }^{\mathrm{AM}}$. (B) Signals observed from constitutively-expressed sfGFP cellfree reactions with different formulations. The sensor only responded to DAPG in the absence of the phIABC operon plasmid. (C) Signals observed when cell-free reactions were constructed by first expressing the phIABC operon in E. coli and combining with the plasmids in an extract from WT E. coli. (D) Optimization of formulations by maximizing response to PG and DAPG when altering the ratio of phIABC-enriched extracts to WT extracts. (D) Total and soluble protein produced in cell extracts containing $p h I A B C$ plasmid, as measured via radioactive $\left({ }^{14} \mathrm{C}\right)$ leucine incorporation. Error bars represent the standard deviation from three independent experiments performed on different days. 


\section{Supplementary Figure 4}

A

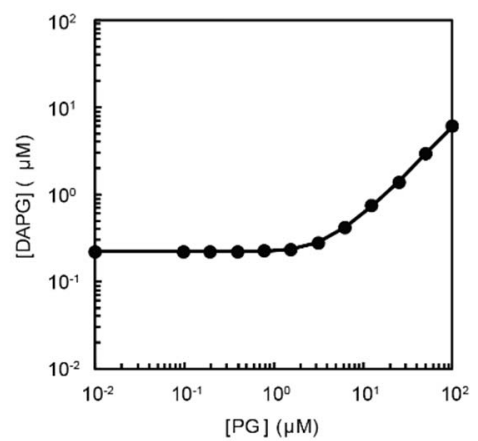

B

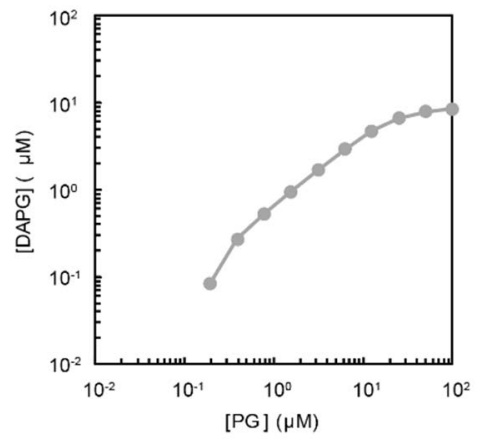

Sensor system conversion of provided PG to DAPG. Conversion of input PG to DAPG with PhIFAM in (A) mid-log phase and (B) stationary phase. DAPG concentrations were inferred from Hill functions fit to the response curves (Methods). 


\section{Supplementary Figure 5}
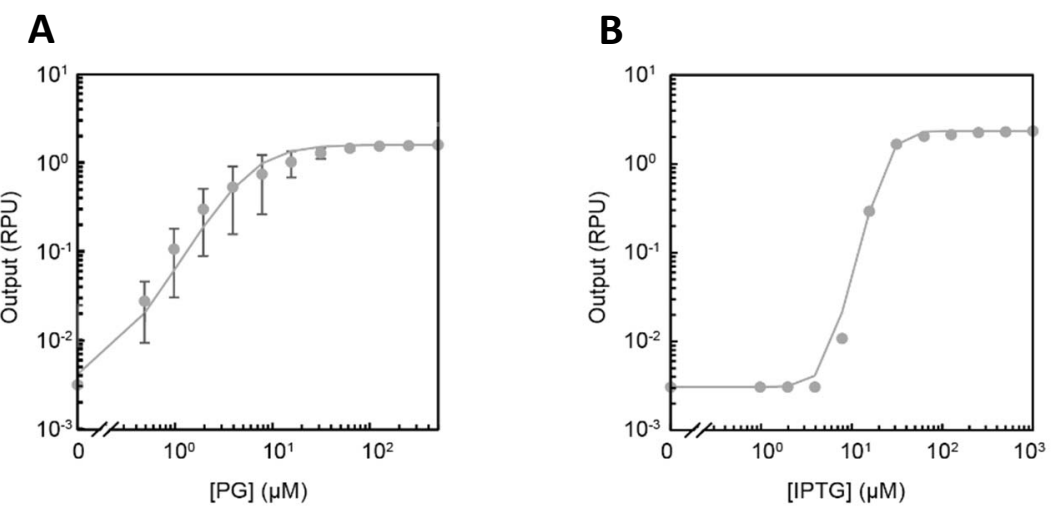

Response of cell-based sensing system to PG and induction with IPTG. (A) Response of cell-based sensing system to PG in stationary growth phase, using the evolved sensor protein PhIF ${ }^{A M}$. Response of measured YFP fluorescence to inferred PG concentration $\left(K_{d}=7.5 \mu M\right)$. (B) Response of sensing system to induction of PhIABC expression by addition of IPTG, indicating dependence of the fluorescence response to PhIABC expression, using the evolved sensor protein PhIF ${ }^{\mathrm{VIN}}$. Error bars represent the standard deviation from three independent experiments performed on different days. 


\section{Supplementary Figure 6}

A

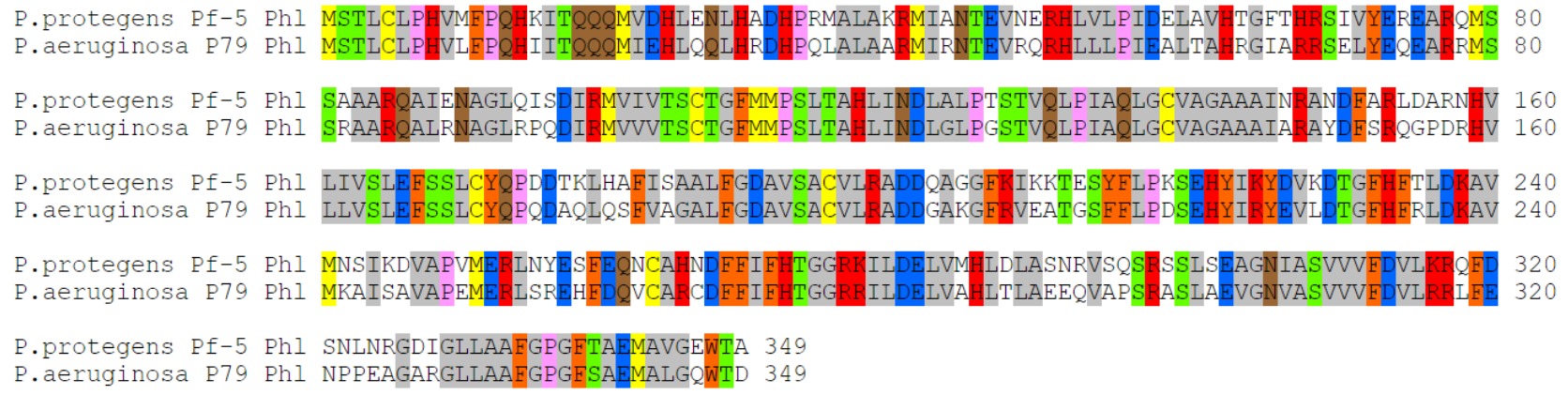

B

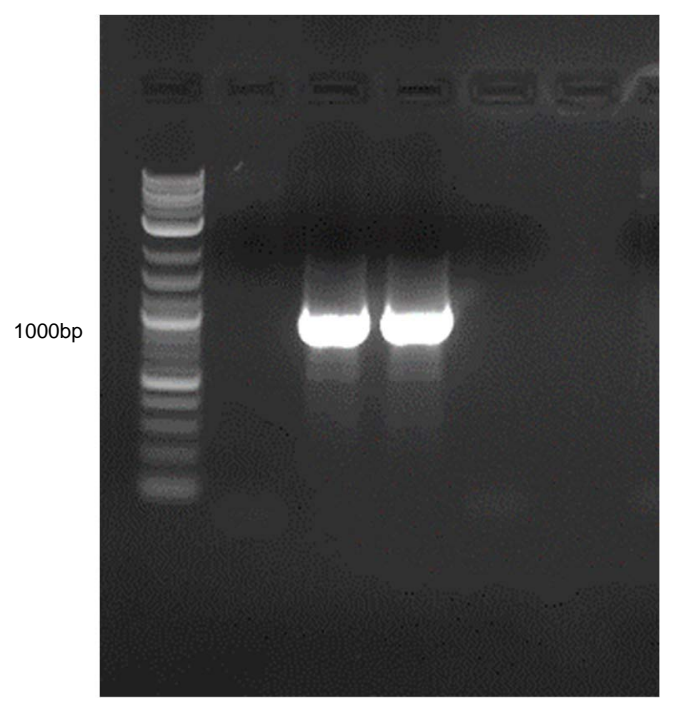

Sequence comparison and PCR gels of phID variants amplified from the aircraft library. (A) Amino acid alignment of Pf-5 PhID with the variant encoded by the gene isolated from strain P. aeruginosa P79. (B) DNA gel of PCR products showing amplification of the phID gene from $P$. aeruginosa P79 (lane 2). An identical gene was also amplified from $P$. aeruginosa WR202 (lane 3) but was not processed further. 


\section{Supplementary Figure 7}

A

$10 \mathrm{nM}$ repressor plasmid $20 \mathrm{nM}$ reporter plasmid

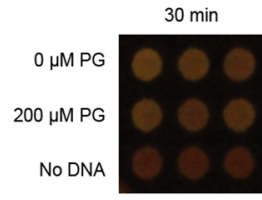

$60 \mathrm{~min}$
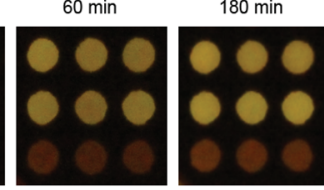

\section{C}

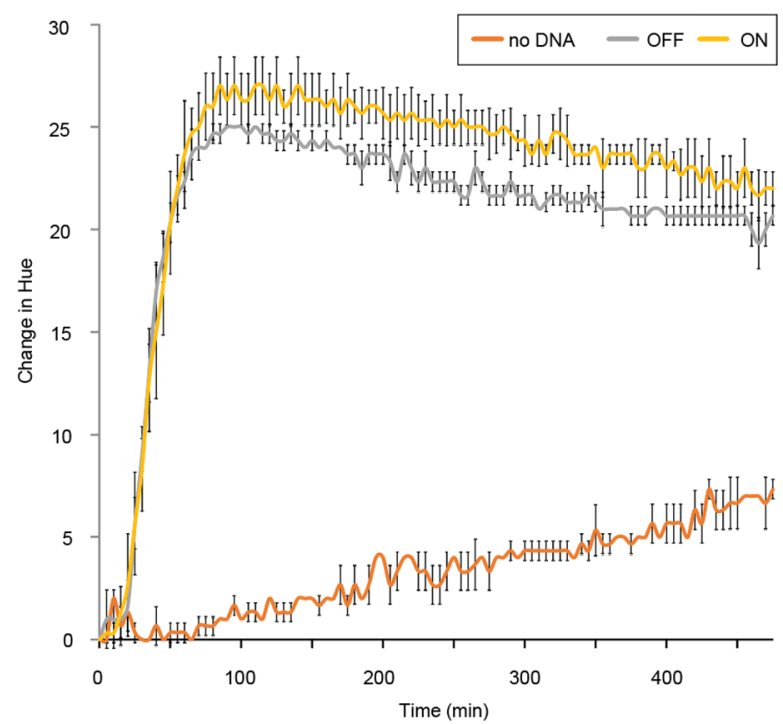

B

$5 \mathrm{nM}$ repressor plasmid

$10 \mathrm{nM}$ reporter plasmid
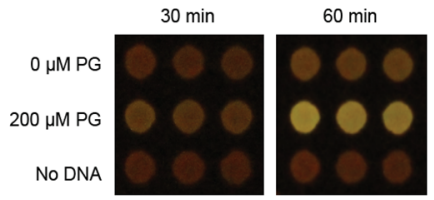

$180 \mathrm{~min}$

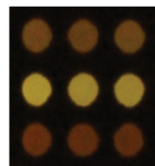

D

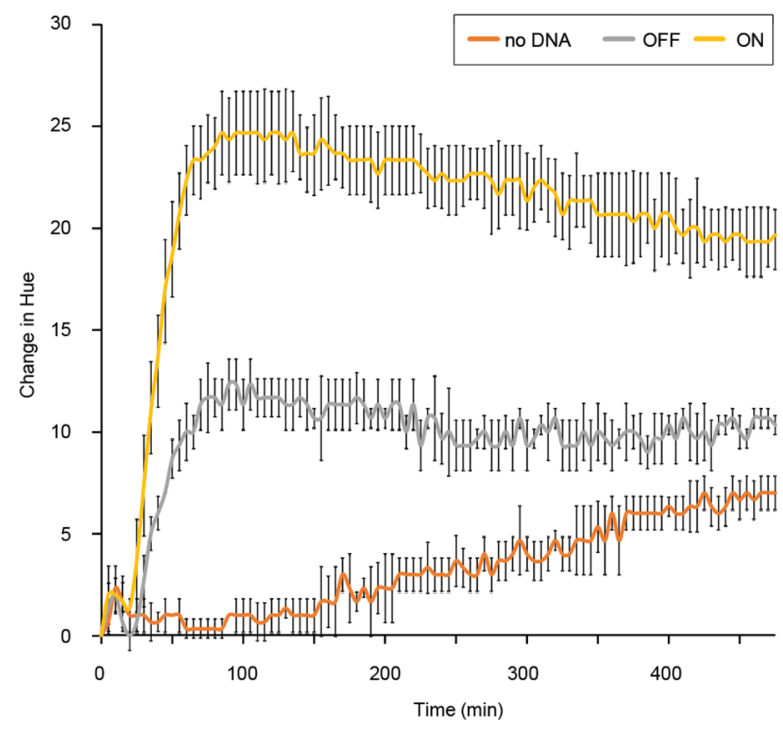

Response of paper-based sensor to PG. Response of paper ticket sensors to PG over eight hours in two formulations, as measured by an automated photography system. (A) Example images of the paperbased PG sensor formulated with $10 \mathrm{nM}$ repressor plasmid and $20 \mathrm{nM}$ reporter plasmid. (B) For comparison, the images of the better-performing formulation from Figure $3 \mathrm{H}$ are shown, using $5 \mathrm{nM}$ repressor plasmid and $10 \mathrm{nM}$ reporter plasmid (C) Time-course observed using the formulation in (A). (D) Time-course observed of formulation in (B) and Figure $3 \mathrm{H}$. Error bars represent the standard deviation from three independent experiments performed on different days. 


\section{Supplementary Figure 8}

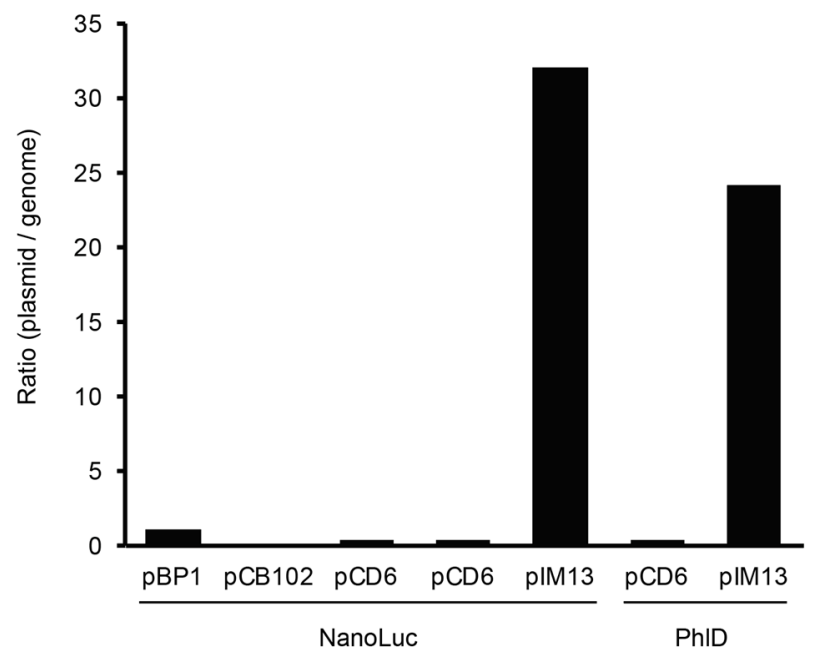

Determination of plasmid copy number in Clostridium by qPCR. Plasmid copy number relative to genomic DNA was determined for $C$. acetobutylicum strains harboring plasmids with different replication origins by quantitative PCR (Methods). 


\section{Supplementary Figure 9}

A
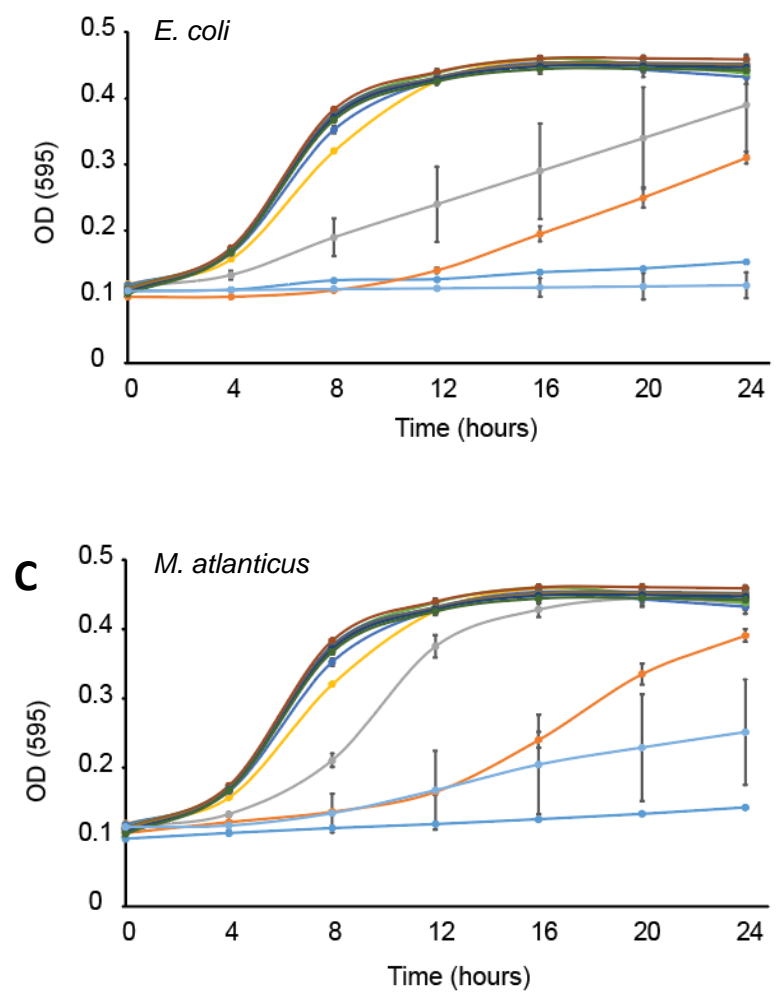

B

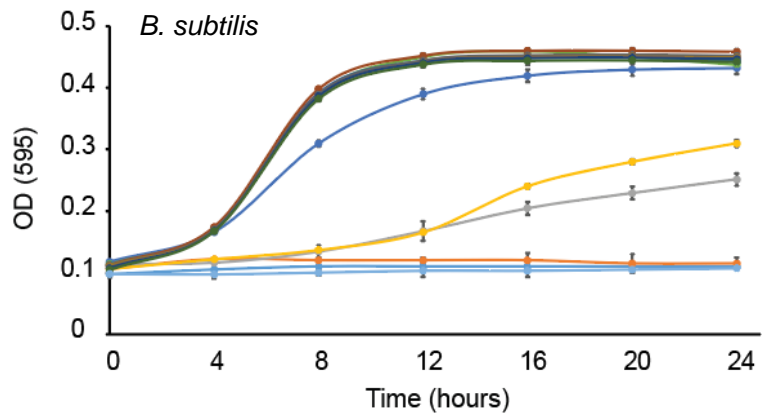

Growth inhibition of E. coli, B. subtilis, and Marinobacter by PG. Data are shown for (A) E. coli, (B), B. subtilis, and (C) M. atlanticus. Error bars represent the standard deviation from three biological replicates. Each organism was grown overnight, diluted 110-fold and cultured while being exposed to increasing concentrations of PG $(0.007,0.015,0.03,0.06,0.12,0.23,0.47,0.94,1.875,3.75,7.5$ and 15 g/L PG). E.coli was grown in EZ-Rich media with kanamycin serving as a negative control. B. subtilis was grown in 2XYT media with kanamycin serving as a negative control. Marinobacter was grown in BB rich media with DMSO serving as a negative control. 
Supplementary Figure 10

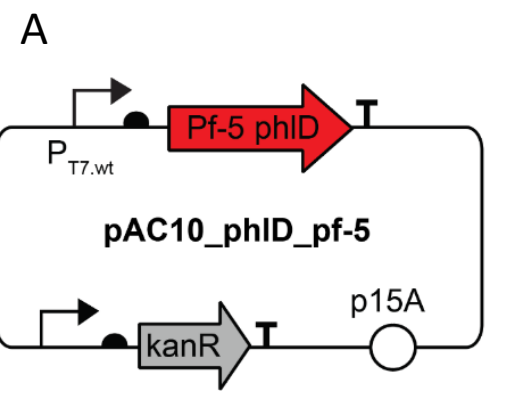

B

C

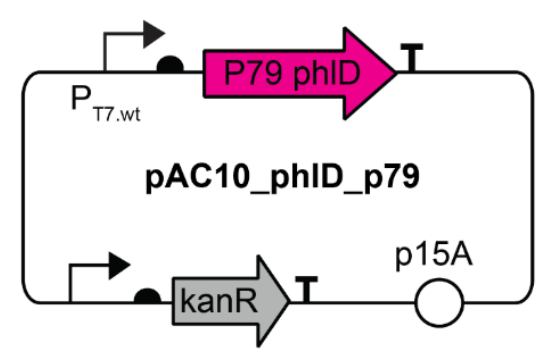

D
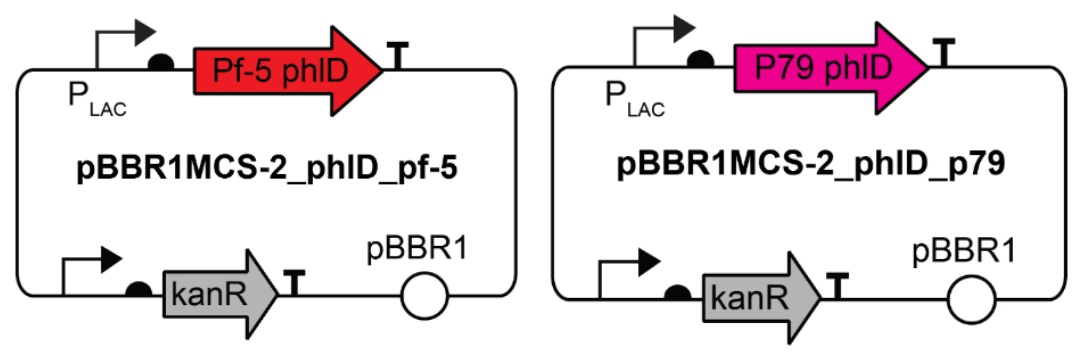

E

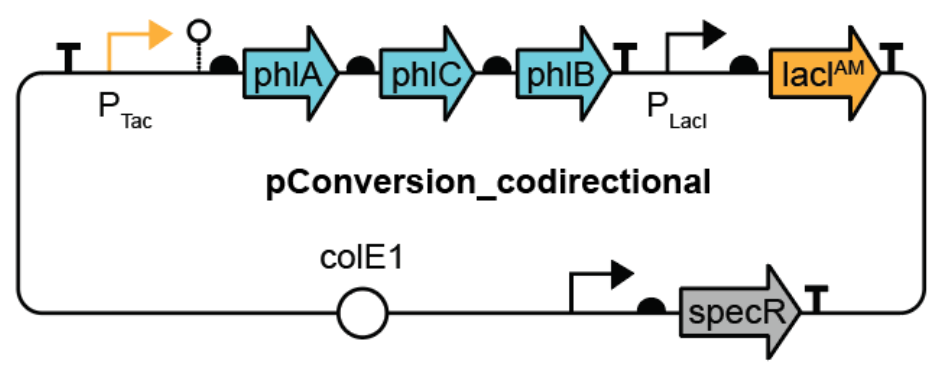

F

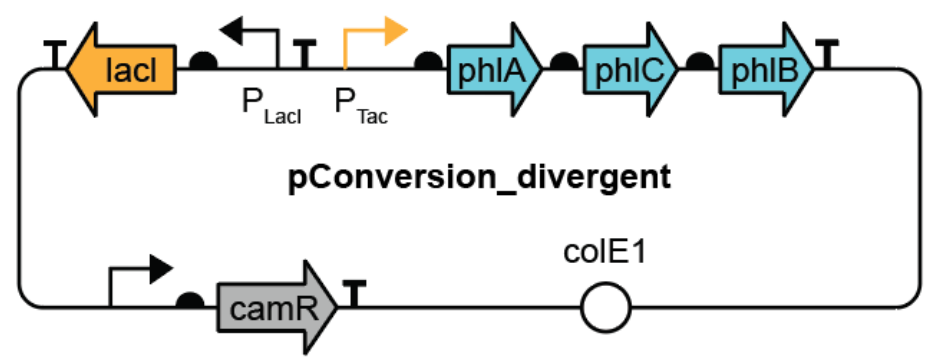



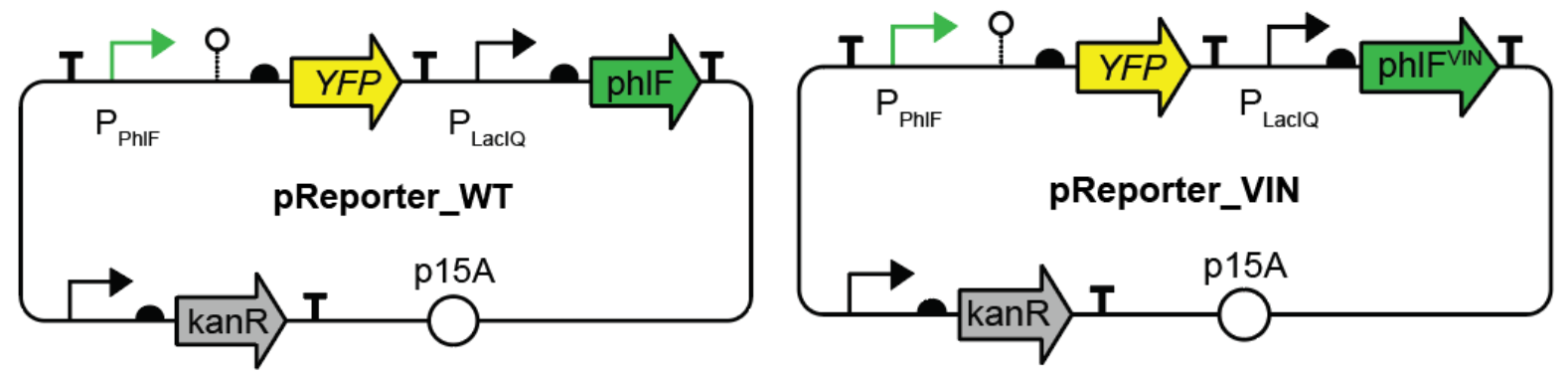

I

J
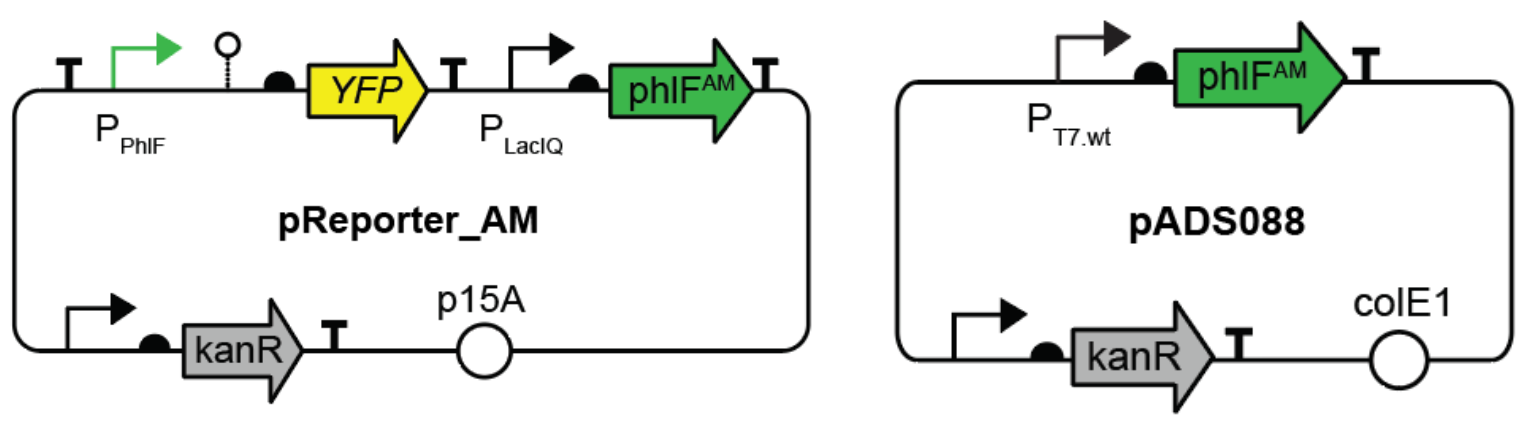

K

$\mathrm{L}$
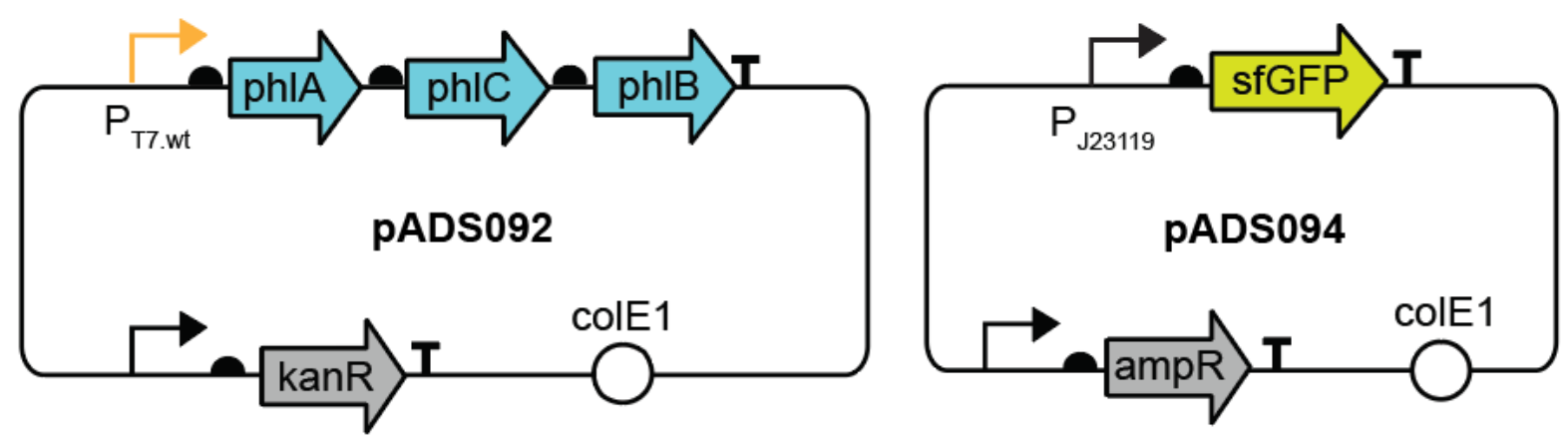

Selection of plasmids utilized in this study. (A-B) Plasmids for PG biosynthesis in E. coli. Each plasmid encodes a variant of the PhID enzyme (a: Pf-5, b: P79) and the expression is controlled by a T7 promoter. (C-D) Plasmids for PG biosynthesis in Marinobacter atlanticus CP1. Each plasmid encodes a variant of the PhID enzyme inserted between the BamHI and $\mathrm{Kpnl}$ sites of the multiple cloning site. Expression is controlled by a lac-driven promoter. (E-I) Plasmids used for the indirect detection of PG. (E-F) Plasmids encode the phIACB operon for conversion of PG to 2,4-diacetylphloroglucinol (DAPG) using either a divergent or co-directional gene orientation. (G-I) Plasmids encoding PhIF sensor variants controlled by a lac-driven promoter. (J-L) Plasmids utilized in the cell-free experiments. (J) Plasmid encoding the PhIF ${ }^{\text {AM }}$ regulator under the control of a T7 promoter (pADS088). (K) Plasmid encoding expression of an optimized phIACB operon (pADS092). (L) Plasmid encoding the optimized GFP reporter (pADS094). 
Supplementary Table 1: Primer table and PCR specifications

\begin{tabular}{|c|c|c|c|}
\hline Primer set name & $\begin{array}{l}\text { Forward primer } \\
\text { Reverse primer } \\
\left(5^{\prime}-3^{\prime}\right)\end{array}$ & $\begin{array}{l}\text { Expected } \\
\text { amplicon } \\
\text { length (bp) }\end{array}$ & Description \\
\hline $\begin{array}{l}\text { Seq ID No } 1 \\
\text { Seq ID No } 2\end{array}$ & $\begin{array}{l}\text { CGGTTACCTTGTTACGACTT } \\
\text { CGGTTACCTTGTTACGACTT }\end{array}$ & $\sim 1200$ & 12 \\
\hline $\begin{array}{l}\text { B2BF } \\
\text { BPR4 }\end{array}$ & $\begin{array}{l}\text { ACCCACCGCAGCATCGTTTATGAGC } \\
\text { CCGCCGGTATGGAAGATGAAAAAGTC }\end{array}$ & 628 & 13 \\
\hline $\begin{array}{l}\text { B2BF-217 } \\
\text { BPR4 }\end{array}$ & $\begin{array}{l}\text { GARCRBGMRGCCCGSCRVATGTC } \\
\text { CCGCCGGTATGGAAGATGAAAAAGTC }\end{array}$ & 608 & This study and ${ }^{13}$ \\
\hline $\begin{array}{l}\text { PhID_subA1_start_F } \\
\text { PhID_subA1_1065_R }\end{array}$ & $\begin{array}{l}\text { ATGCCAACGCTTTGTTGTCCGGCCATT } \\
\text { TCATGGTAAAACCTCCCTGTTGTTCCAT }\end{array}$ & 1065 & This study \\
\hline $\begin{array}{l}\text { PhlD_subB_startF } \\
\text { PhID_subB_1073R }\end{array}$ & $\begin{array}{l}\text { ATGTCGACGCTCTGTCTTCCCCACGTA } \\
\text { TCAGTCCGTCCACTGTCCCAGCGCCAT }\end{array}$ & 1050 & This study \\
\hline $\begin{array}{l}\text { PhlD_subC_start_F } \\
\text { PhID_subC_end_1050_R }\end{array}$ & $\begin{array}{l}\text { ATGTCGACTCTTTGCCAACCCCACGTA } \\
\text { TCAGGCTGCCCATTCACCGAGTGCCAT }\end{array}$ & 1050 & This study \\
\hline $\begin{array}{l}\text { PhlD_subD_F_start } \\
\text { PhID_subD_R_stop_1050 }\end{array}$ & $\begin{array}{l}\text { ATGTCTACACTTTGCCTTCCACACGTC } \\
\text { TCAGGCGGTCCACTCGCCCACCGCCAT }\end{array}$ & 1050 & This study \\
\hline $\begin{array}{l}\text { PhlD_subE_F_start } \\
\text { PhID_subE_R_stop_1050 }\end{array}$ & $\begin{array}{l}\text { ATGTCTACTCTTTGTCTCCCACACGTA } \\
\text { TCAGGCCGCCCATTCACCCACGGA }\end{array}$ & 1050 & This study \\
\hline $\begin{array}{l}\text { PhID_subF_F_start } \\
\text { PhID_subF_R_stop_1089 }\end{array}$ & $\begin{array}{l}\text { ATGTCTACTCTTTGCAAACCCAG } \\
\text { TCAGGCCACCCACTTGCCCACGGCCATTTC }\end{array}$ & 1089 & This study \\
\hline $\begin{array}{l}\text { PhID_P.aerug_start_F }{ }^{a} \\
\text { PhID_P.aerug_1073_stop_R }{ }^{a}\end{array}$ & $\begin{array}{l}\text { ggtctctggagaggtatactggtactaggaggtacatATGTCGA } \\
\text { CGCTCTGTCTTCCCCACGTA } \\
\text { ggtctctagtaTCAGTCCGTCCACTGTCCCAGCGCCAT }\end{array}$ & 1098 & This study \\
\hline $\begin{array}{l}\text { phlB_238_F } \\
\text { phlE_1941_R }\end{array}$ & $\begin{array}{l}\text { GCCATGGGYTAYGGCGAARYSGTRCC } \\
\text { GCATGATCASCGGRAACAGCGGC }\end{array}$ & 1704 & This study \\
\hline $\begin{array}{l}\text { PhID_seq_intF } \\
\text { PhID_seq_intR }\end{array}$ & $\begin{array}{l}\text { CCATCTGACGCTCGCCGAGGAG } \\
\text { GCCTCCTGTTCGTATAACTC }\end{array}$ & $n / a$ & This study \\
\hline $\begin{array}{l}\text { qcatPF } \\
\text { qcatPR } \\
\text { q0905F } \\
\text { q0905R } \\
\text { qCAP0098F } \\
\text { qCAP0098R }\end{array}$ & $\begin{array}{l}\text { GCCTTTGGACTGAGTGTAAGT } \\
\text { TGGCTTTCCTTCCATTCTATGA } \\
\text { TGGATTACAAGCAGCCATTTC } \\
\text { AATCCTCCATTCCAAAACCA } \\
\text { GGAACTGGAGATTGAGGATTAACTT } \\
\text { CTCTTAACGTATCAAATGGCAGA }\end{array}$ & $\mathrm{n} / \mathrm{a}$ & $\begin{array}{l}\text { qPCR primers. This } \\
\text { study }\end{array}$ \\
\hline
\end{tabular}

${ }^{a}$ Lower case text indicates Type-Ils sites for cloning into pAC10 


\section{Supplementary Table 2: Shuttle plasmids used to express phID in Clostridium acetobutylicum}

\begin{tabular}{lllc}
\hline Plasmid name & $\begin{array}{l}\text { Gram-positive } \\
\text { replication origin }\end{array}$ & $\begin{array}{l}\text { Promoter/riboswitch } \\
\text { driving phlD }\end{array}$ & Other features \\
\hline pAVT060 & pIM13 & $\mathrm{P}_{\text {thl }} /$ TheoRS_E & - \\
\hline pAVT061 & pBP1 & $\mathrm{P}_{\text {thl }} /$ TheoRS_E & - \\
\hline pAVT062 & PCB102 & $\mathrm{P}_{\text {thl }} /$ TheoRS_E & - \\
\hline pAVT063 & PCD6 & $\mathrm{P}_{\text {thl }} /$ TheoRS_E & - \\
\hline pAVT080 & pIM13 & $\mathrm{P}_{\text {thl }} /$ no riboswitch & - \\
\hline pAVT089 & pIM13 & $\mathrm{P}_{\text {thl }} /$ TheoRS_E & C-terminal HA tag on PhID \\
\hline
\end{tabular}

Elements common to all plasmids in table: ColE1 Gram-negative replication origin, chloramphenicol acetyltransferase providing resistance to chloramphenicol or thiamphenicol, CD0164 and Cpa fdx bidirectional terminators flanking the phID expression cassette. 
Supplementary Table 3: Optimization of a cell-free DAPG-responsive promoter

\begin{tabular}{cclc}
\hline Promoter & $\begin{array}{l}\text { (-) repressor, } \\
(-) \text { DAPG }\end{array}$ & $\begin{array}{l}\text { (+) repressor, } \\
(-) \text { DAPG }\end{array}$ & $\begin{array}{l}\text { (+) repressor, } \\
(+) \text { DAPG }\end{array}$ \\
\hline \multicolumn{2}{l}{ Cell-free extract, batch 1} \\
\hline pTac-phlO & $0.051 \pm 0.004$ & $0.010 \pm 0.001$ & - \\
\hline pT7-phlO & $0.180 \pm 0.006$ & $0.164 \pm 0.001$ & - \\
\hline J23119-phlO & $0.592 \pm 0.029$ & $0.151 \pm 0.011$ & - \\
\hline \multicolumn{2}{l}{ Cell-free extract, batch 2} \\
\hline J23119-phlO & $2.29 \pm 0.48$ & $0.52 \pm 0.02$ & $1.96 \pm 0.10$ \\
\hline
\end{tabular}

Reported data are micromolar equivalents of fluorescein isothiocyanate (FITC) based on a previously developed standard curve, with error equal to the standard deviation of three technical replicate measurements. 
Supplementary Table 4: Genetic part sequences

\begin{tabular}{|c|c|c|c|}
\hline Part Name & Part Type & Sequence & $\begin{array}{l}\text { Reference/ } \\
\text { Source }\end{array}$ \\
\hline Pf-5 PhID & Gene & 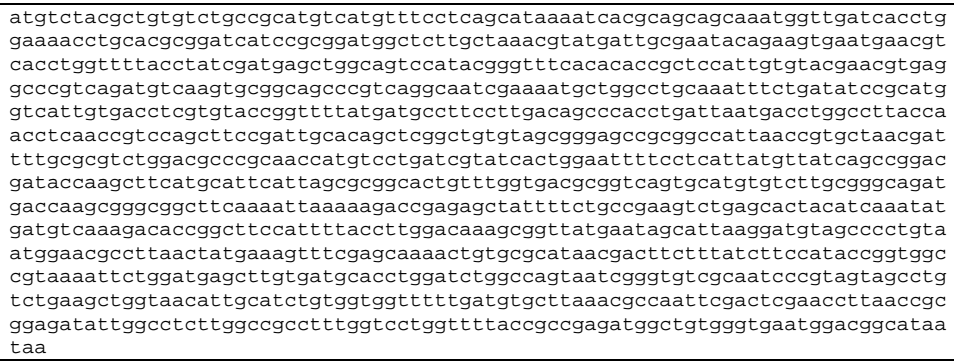 & $\begin{array}{c}\text { https://biocyc. } \\
\text { org/ }\end{array}$ \\
\hline P79 PhID & Gene & 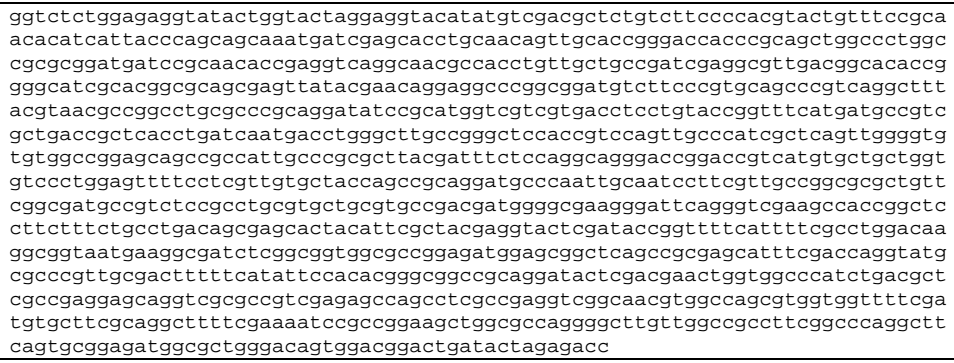 & This study \\
\hline PhID (4x-2) & Gene & $\begin{array}{l}\text { atgagcactttatgcttgccacatgttatgtttccacaacacaagataactcagcaacagacagtggatcactta } \\
\text { gaggacctacacgctgatcacccaaggatggcattggcaaagagaatgattgcaaatacagaggttaacgaaagg } \\
\text { caccttgtattgcctattgacgaattagcagtgcacacaggattcacacataggtcaatagtatatgagagggaa } \\
\text { gcaaggcagatgtcatcaacagctgcaagacaagcaattgaaaacgcaggacttcagatttcagacattaggatg } \\
\text { gtgatagttacttcatgtacaggttttatgatgccatctctaactgctcacttaataaacgatttagctctacca } \\
\text { actagtacagttcagttgcctatagctcaattaggatgtgtggcaggtgcagctgctattaatagggctaacgac } \\
\text { ttcgcaagactagacgctaggaatcacgtactaatagtcattagagttcagctcactatgctaccaaccagac } \\
\text { gacactaaacttcacagttttattagtgcagcattgttggagactgttctgcttgtgttgagagcagac } \\
\text { gaccaagcaggtggattcaaataaaaaactgagtcttattttgcctaagagtgaacattatattaaatat } \\
\text { gatgttaaggacacaggtttcacttcactctagacaagctgtaatgaatagtataaaggacgtagcacctgta } \\
\text { atggaaagacttaattatgagagttcgagcagaactgcgctcataacgacttcttatattccatactggtgga } \\
\text { agaaaatacttgatgaactagtaatgcacttggatcttgcatcaaatagggtaagccagagtagaagtagtctt } \\
\text { agtgaagctggtaacatagcttcagttgttgttttgacgtactaaagagacagtttgattcaaatcttaataga } \\
\text { ggagacattggtttactagcagcatttggaccaggattcacagcagaaatggcagtaggagaatggactgcatga }\end{array}$ & $\begin{array}{c}4 \\
\text { (Codon- } \\
\text { adapted for } \\
\text { Clostridium) }\end{array}$ \\
\hline phIABC & Operon & 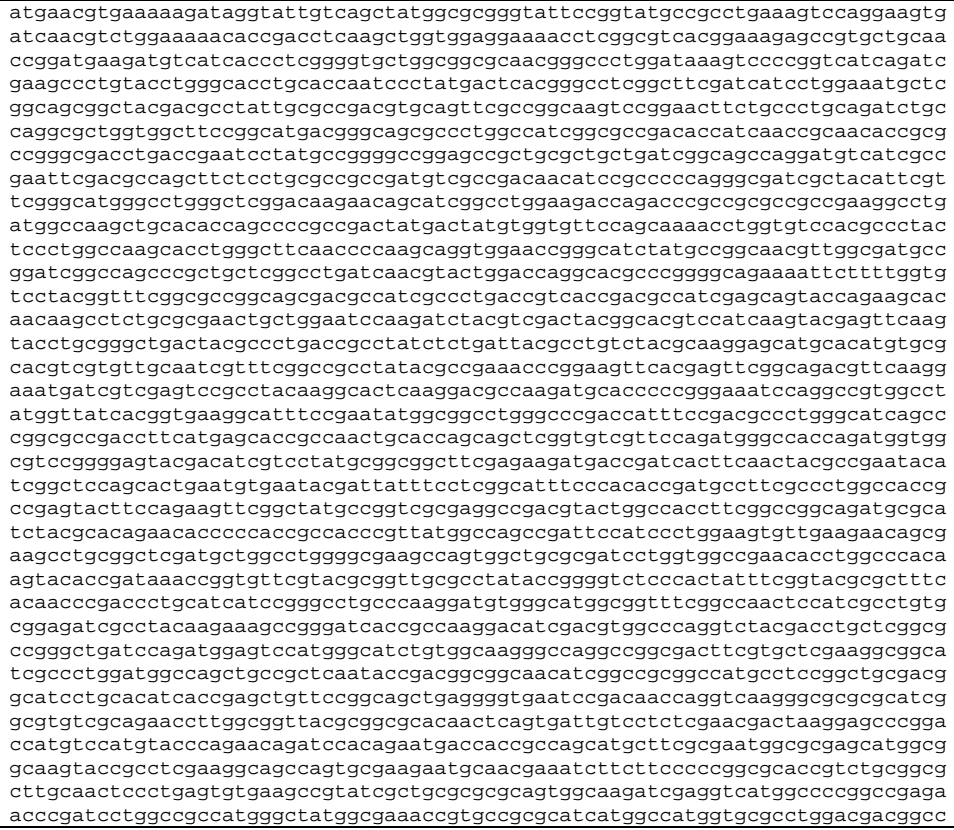 & 14 \\
\hline
\end{tabular}




\begin{tabular}{|c|c|c|c|}
\hline & & $\begin{array}{l}\text { tggtgatcgcttcggaaatcgtcgatgtgtgcgatcagcaacagctgaaagtcggtgcgccggtgcgcatggtga } \\
\text { tccgcaagcatgtgcgcgaaagcaacctggcctggcaatacgcttataagttcgtactcgatatataa }\end{array}$ & \\
\hline WT phlF & Gene & 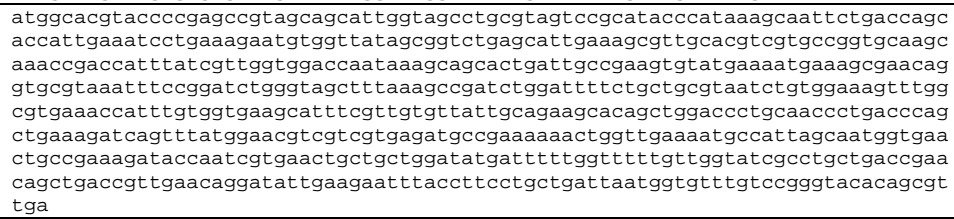 & 14 \\
\hline phIF ${ }^{V I N}$ & Gene & 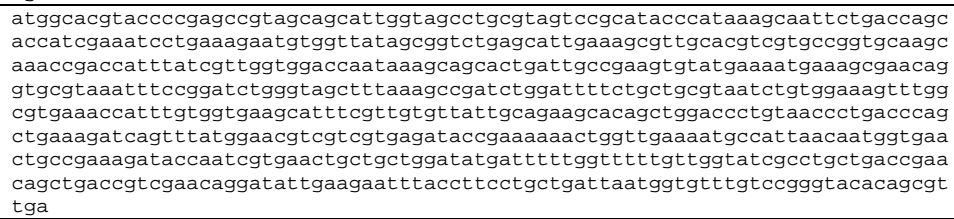 & This study \\
\hline phIF $^{\text {AM }}$ & Gene & 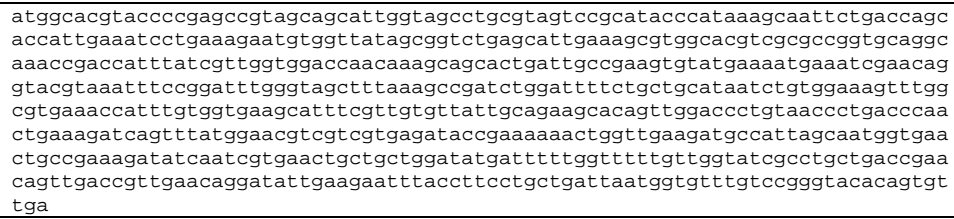 & This study \\
\hline sfGFP & Gene & 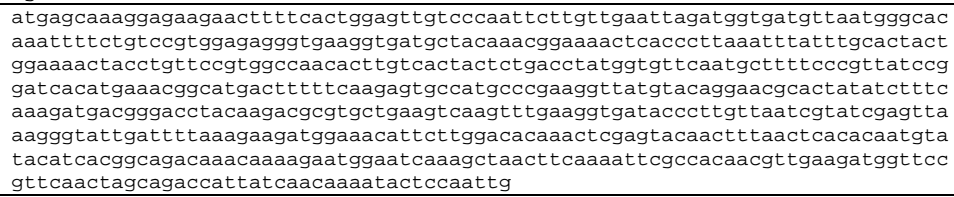 & 15 \\
\hline phlO & Operator & Ggaagagagtcaattcatgggggtgaat & This study \\
\hline phl2 & RBS & ggaagagagtcaattcatgggggtgaat & This study \\
\hline pJL1_RBS & RBS & tactagagtcaagaggaaa & This study \\
\hline L3S2P21 & Terminator & ctcggtaccaaattccagaaaagaggcctcccgaaaggggggccttttttcgttttggtcc & This study \\
\hline $\mathrm{J} 23119$ & Promoter & ttgaca & This study \\
\hline pPhIF & Promoter & atgatacgaaacgtaccg & This study \\
\hline DT11 & Terminator & $\begin{array}{l}\text { acctcaacatctctcgctctaacgcatgaggaagcccccggaagatcaccttccgggggettttttattgcgctc } \\
\text { cttggccctccatccttagatagctcggtaccaaattccagaaaagaggcctcccgaaaggggggcctttttch } \\
\text { ttttggtcctcataggcaatacgatcgcatgtcccgtttcgttccgtactcaca }\end{array}$ & This study \\
\hline pAVT060 & Plasmid & 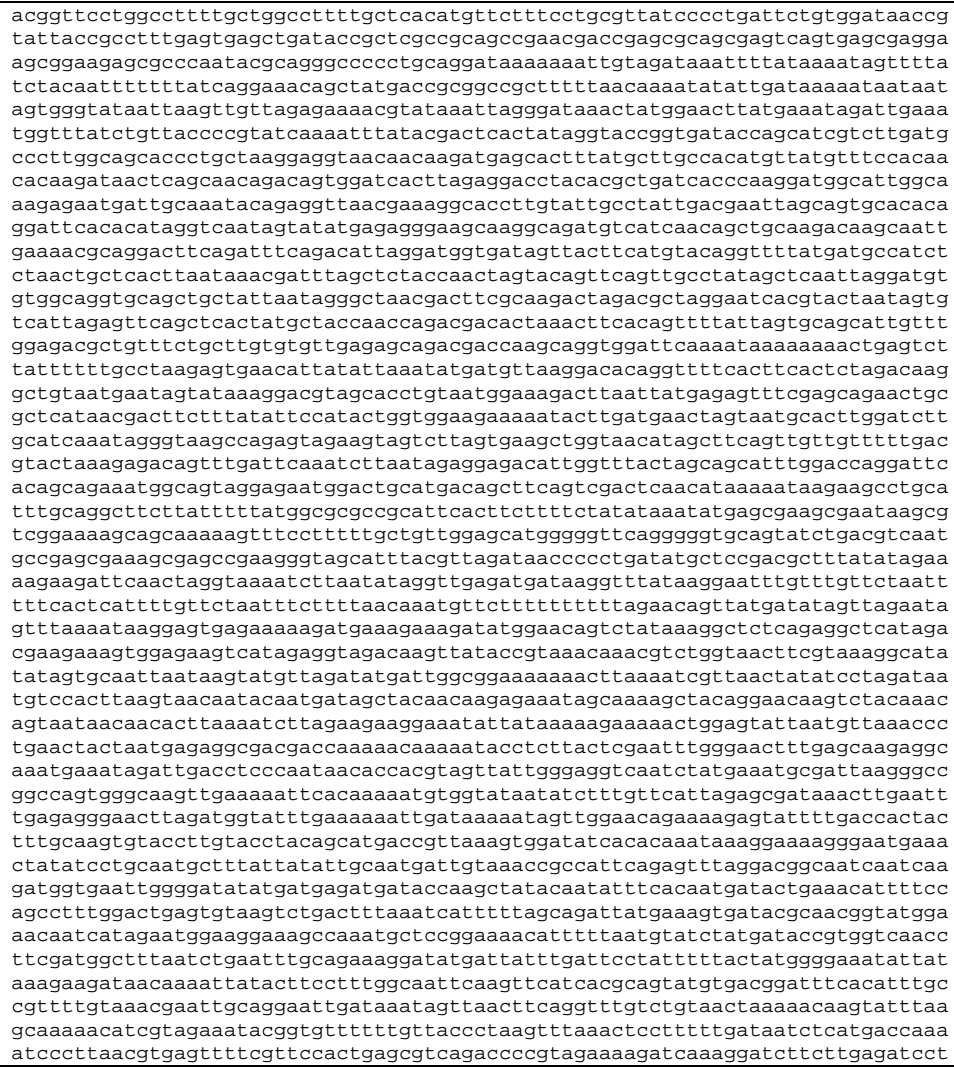 & This study \\
\hline
\end{tabular}




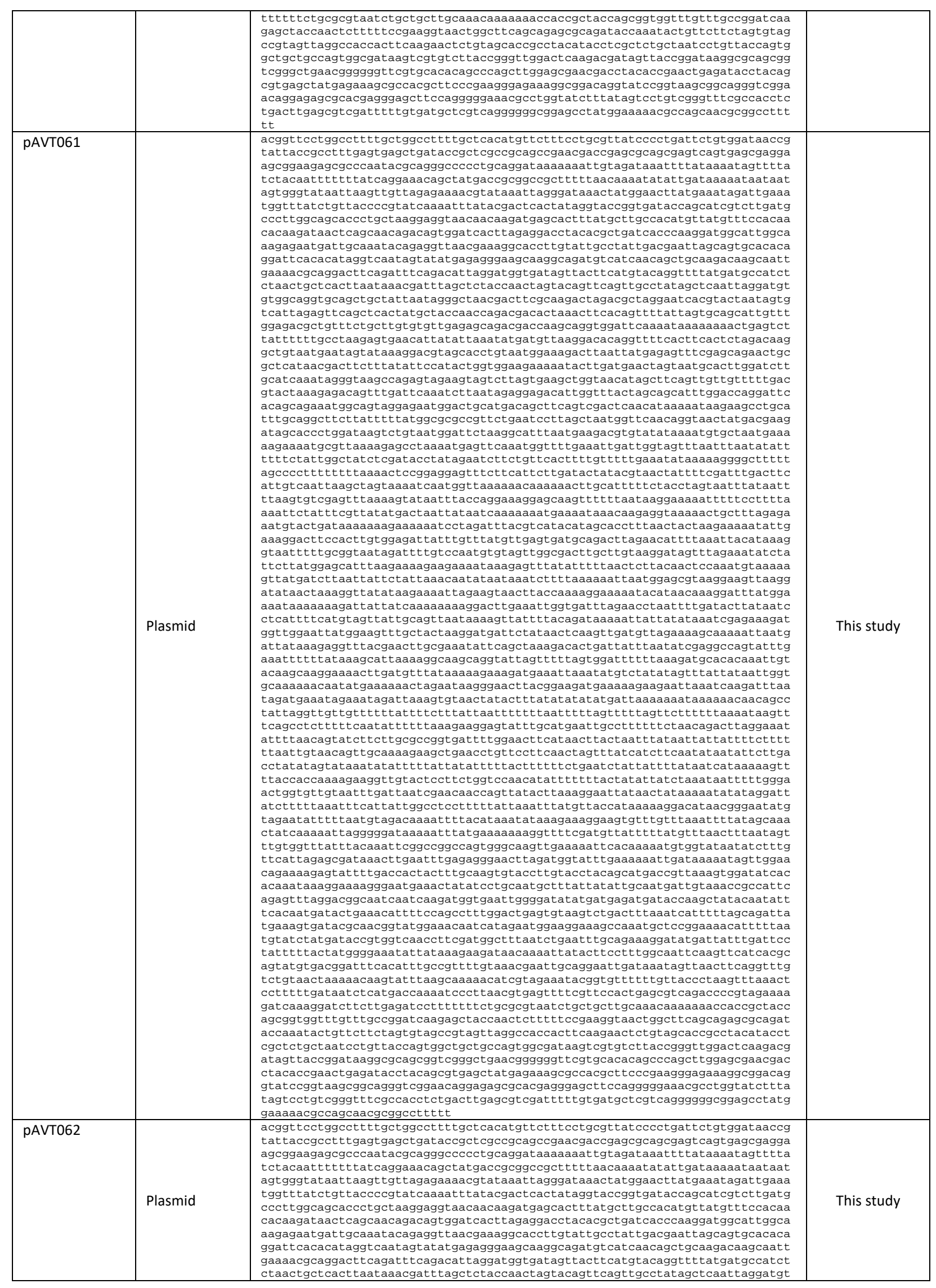




\begin{tabular}{|c|c|c|c|}
\hline & & 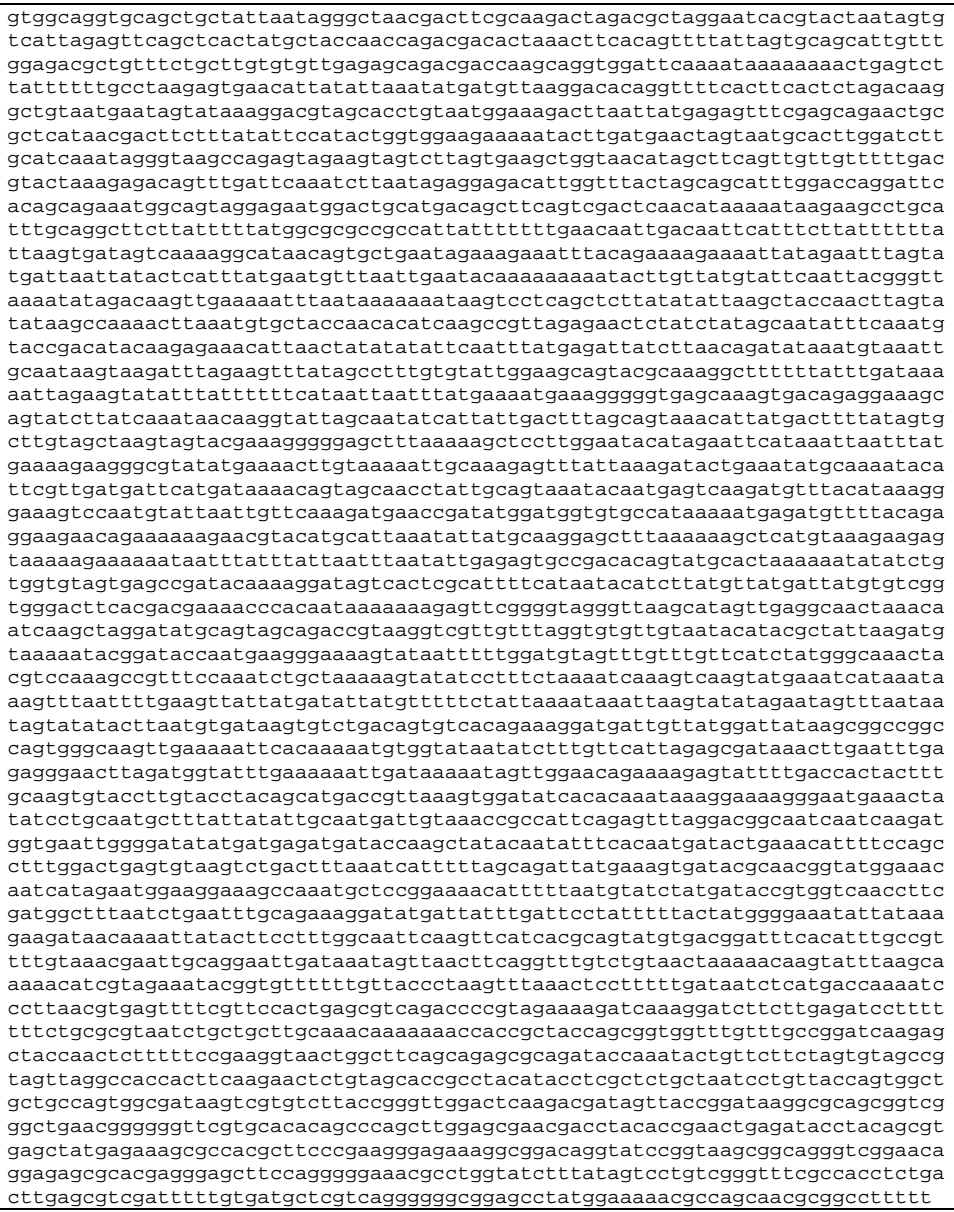 & \\
\hline pAVT063 & Plasmid & 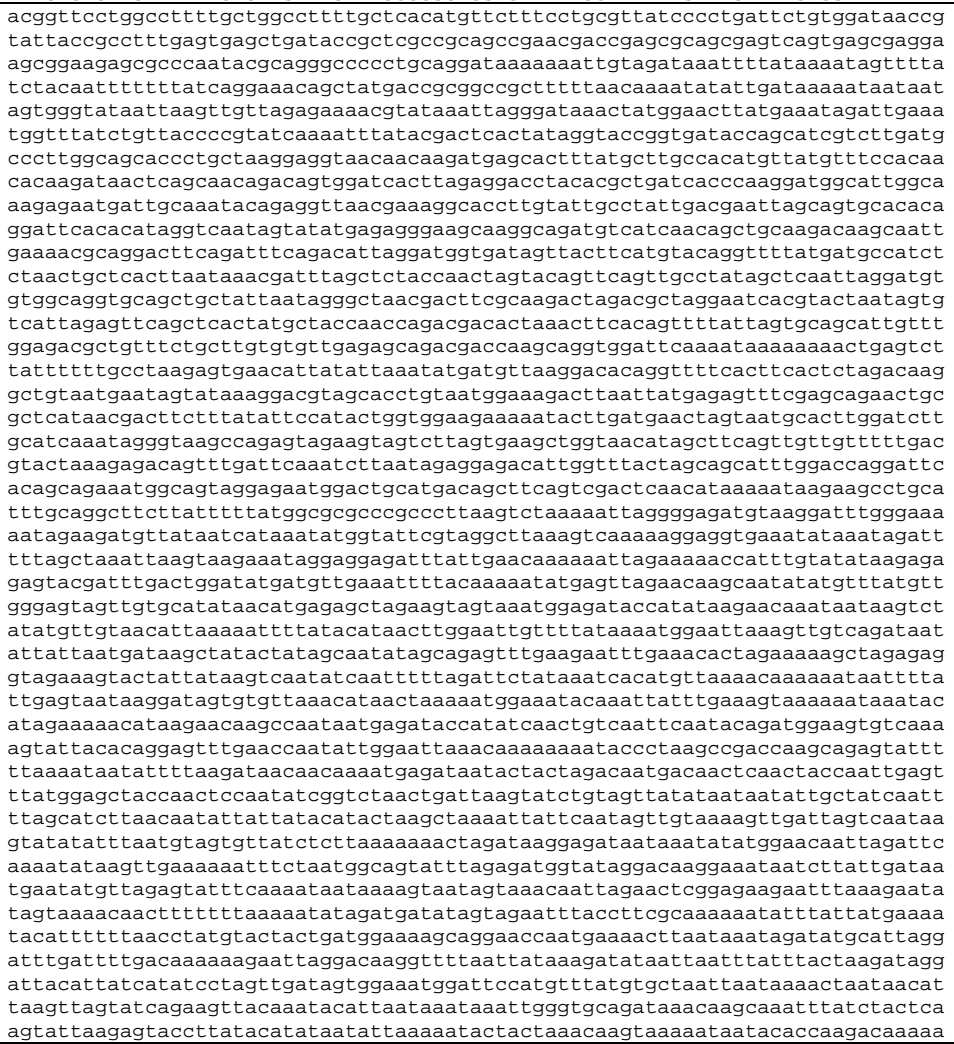 & This study \\
\hline
\end{tabular}




\begin{tabular}{|c|c|c|c|}
\hline & & 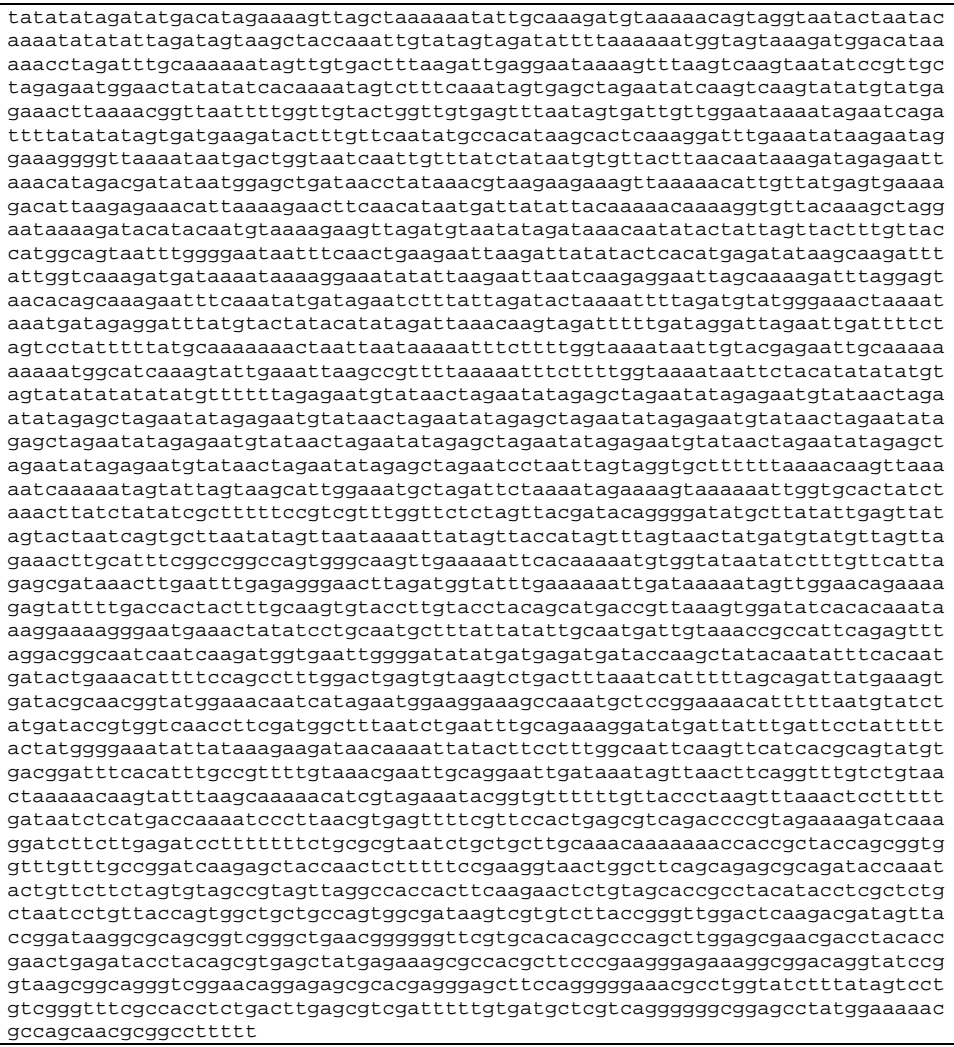 & \\
\hline pAVT080 & Plasmid & 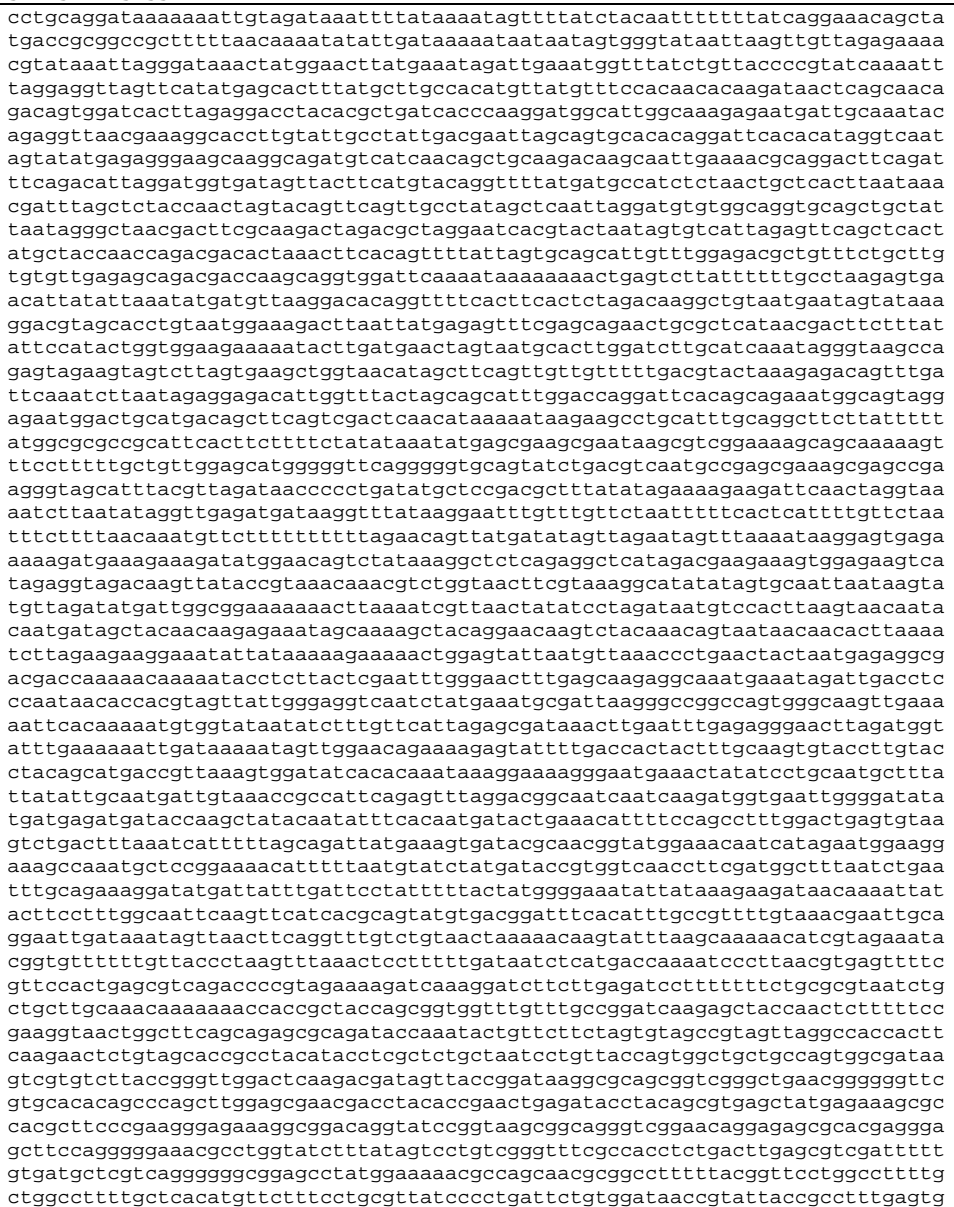 & This study \\
\hline
\end{tabular}




\begin{tabular}{|c|c|c|c|}
\hline & & $\begin{array}{l}\text { agctgataccgctcgccgcagccgaacgaccgagcgcagcgagtcagtgagcgaggaagcggaagagcgcccaat } \\
\text { acgcagggccc }\end{array}$ & \\
\hline pAVT089 & Plasmid & 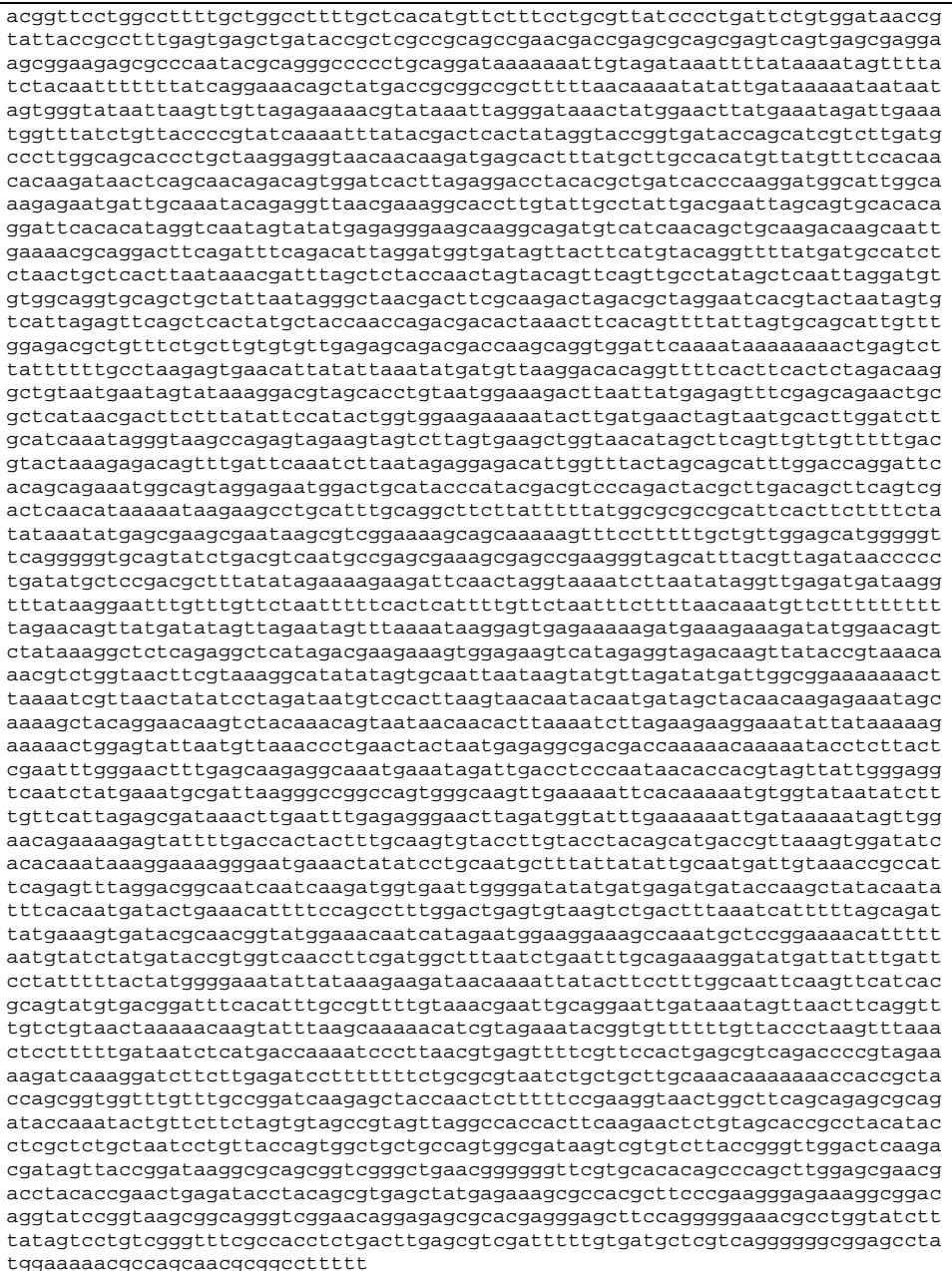 & This study \\
\hline pADS088 & Plasmid & 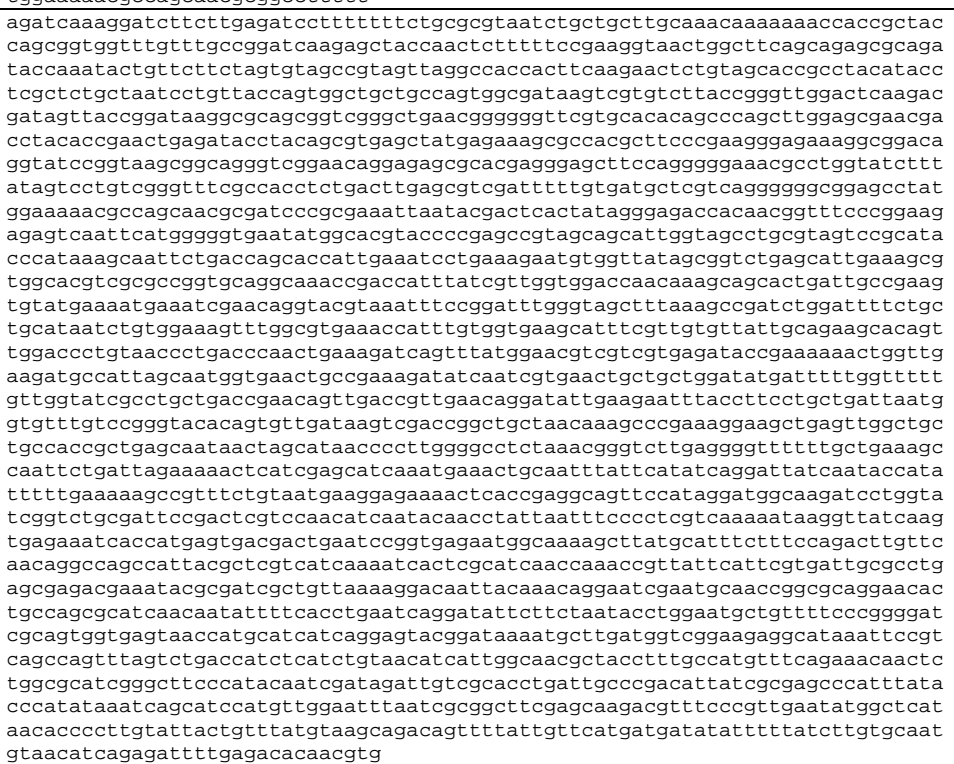 & This study \\
\hline pADS092 & Plasmid & 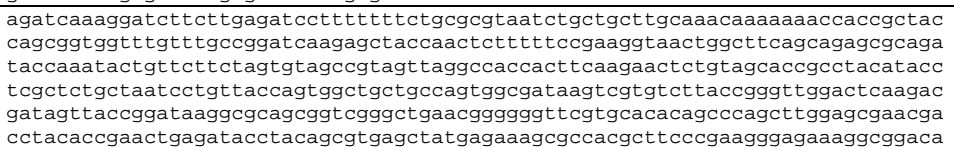 & This study \\
\hline
\end{tabular}




\begin{tabular}{|c|c|c|c|}
\hline & & 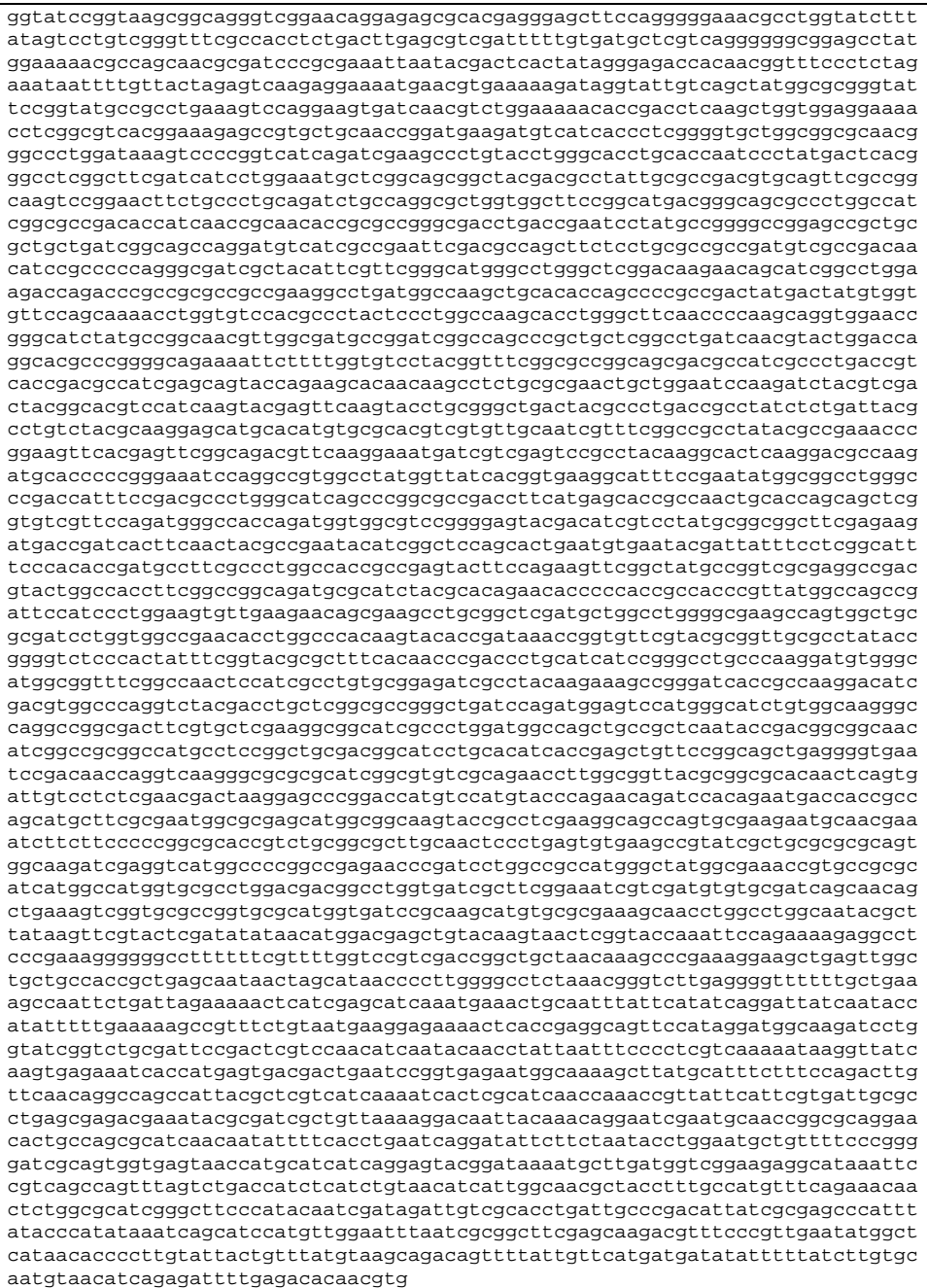 & \\
\hline pADS094 & Plasmid & 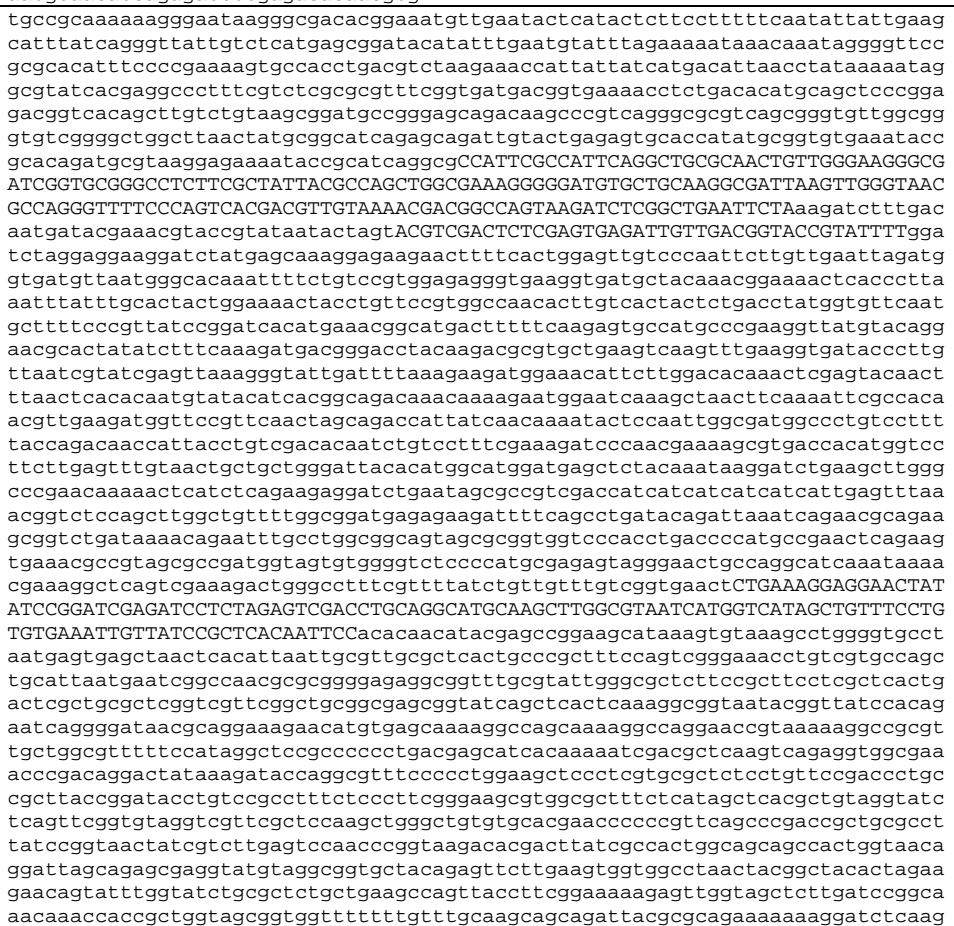 & This study \\
\hline
\end{tabular}




\begin{tabular}{|c|c|c|c|}
\hline & & 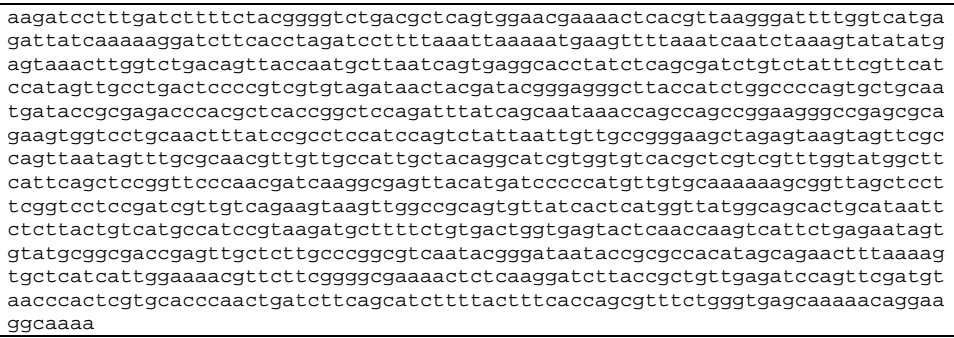 & \\
\hline pAJM & Plasmid & 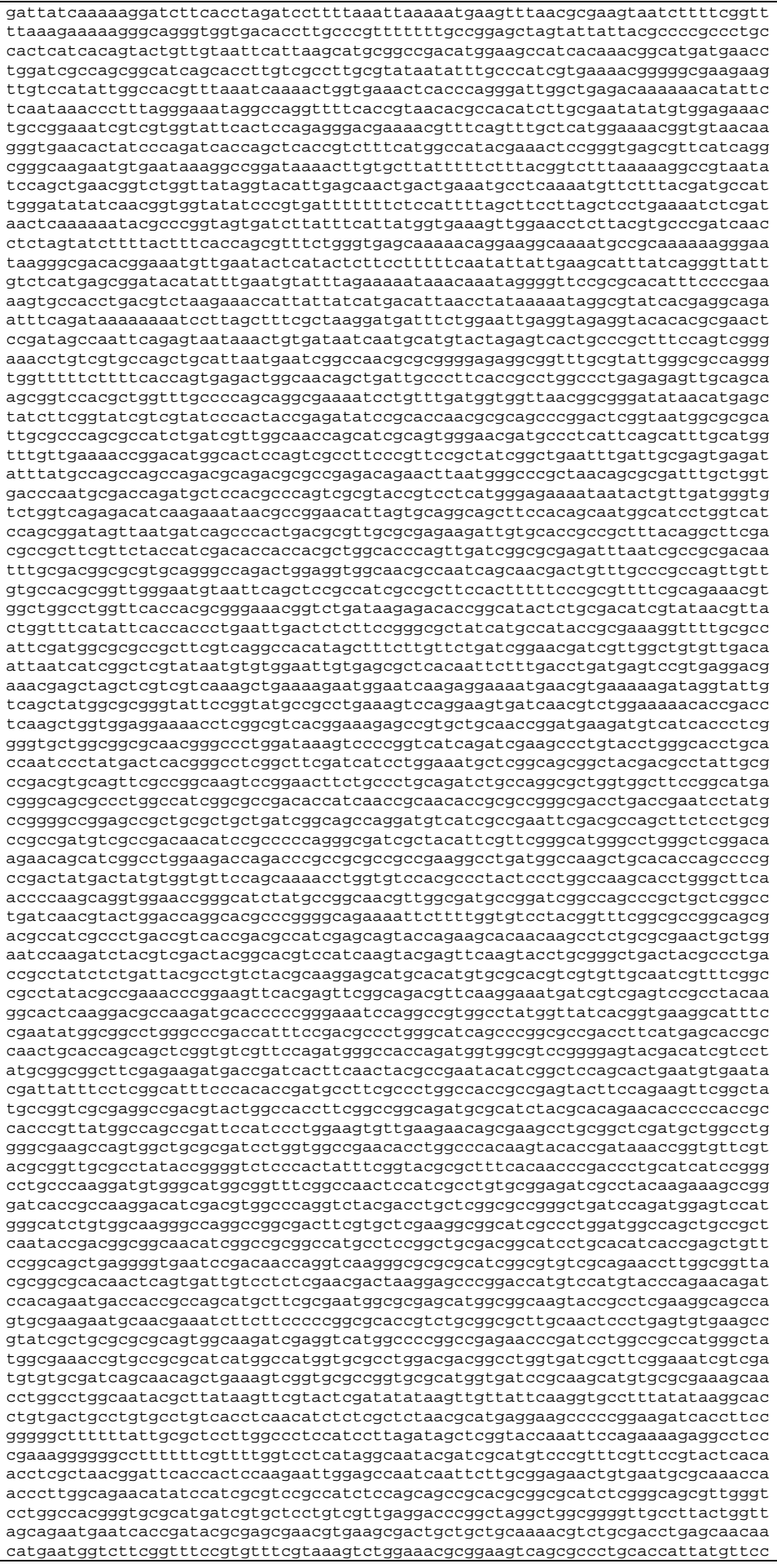 & This study \\
\hline
\end{tabular}




\begin{tabular}{|c|c|c|c|}
\hline & & 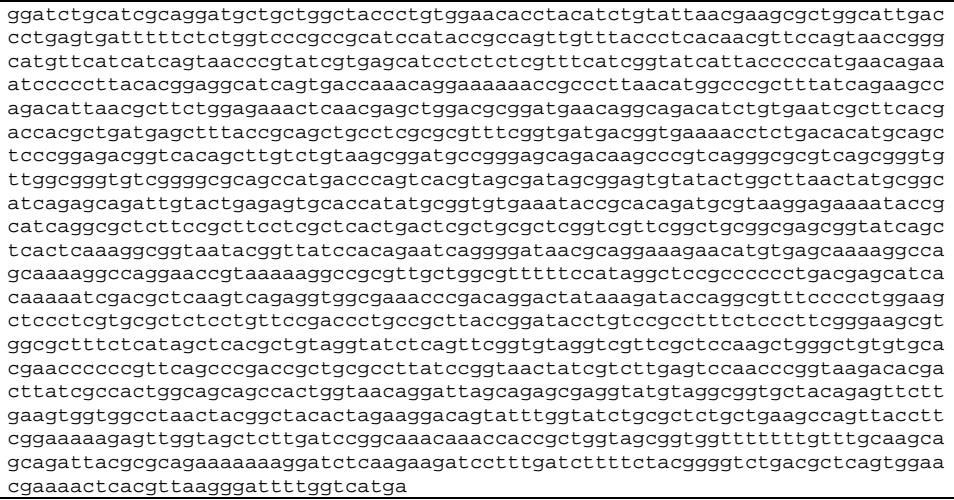 & \\
\hline pAJM.450 & Plasmid & 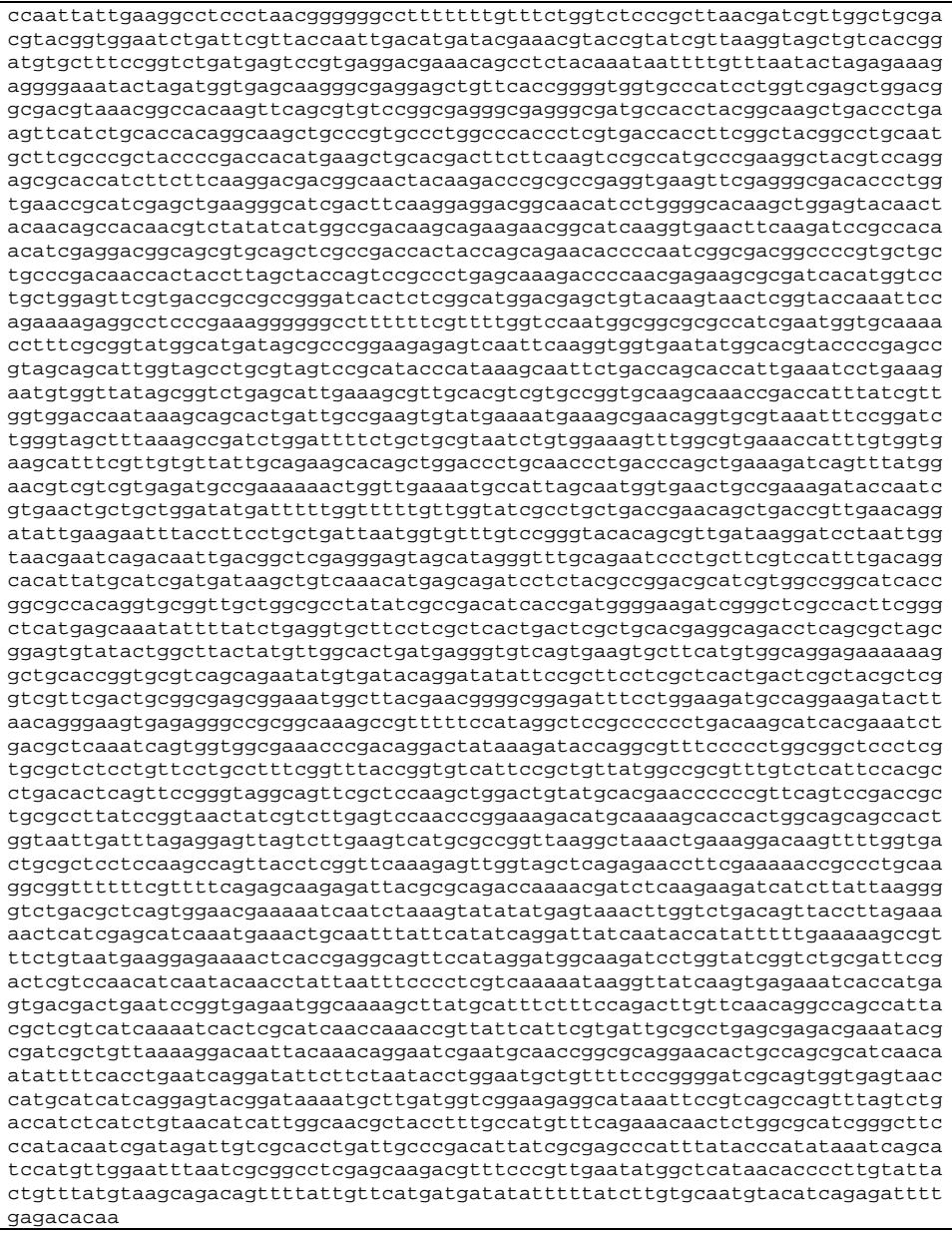 & This study \\
\hline pAJM.452 & Plasmid & 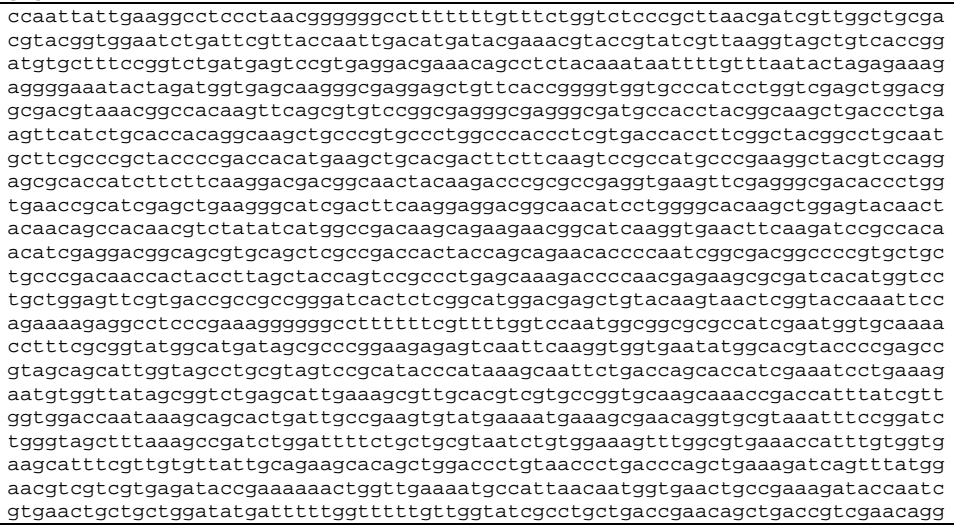 & This study \\
\hline
\end{tabular}




\begin{tabular}{|c|c|c|}
\hline & & 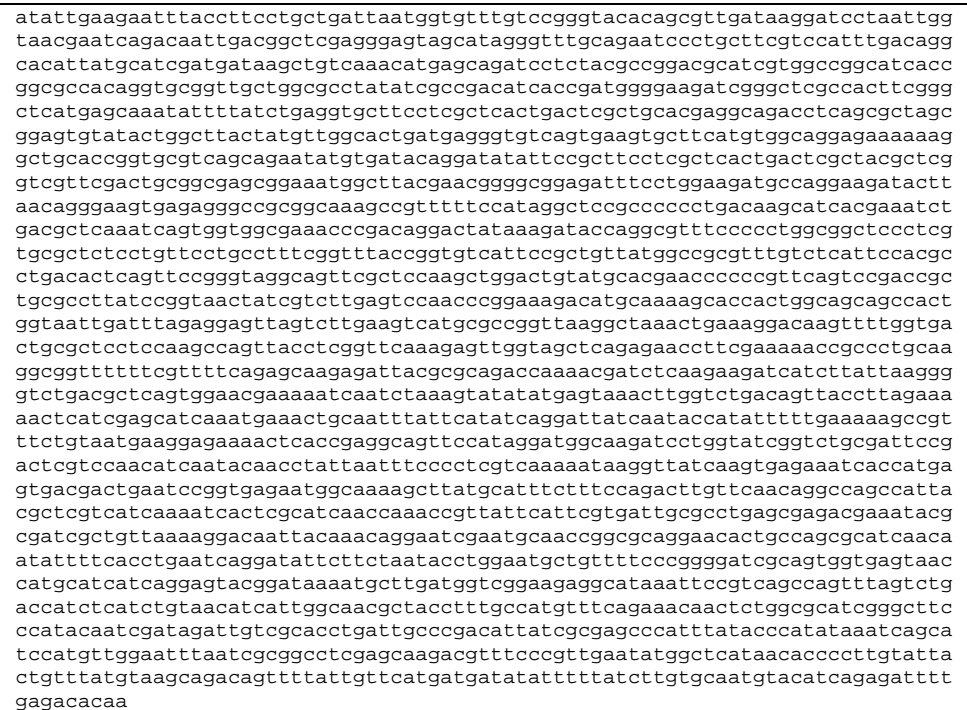 \\
\hline
\end{tabular}




\section{References}

1. Guido, N., Starostina, E., Leake, D., and Saaem, I. (2016) Improved PCR Amplification of Broad Spectrum GC DNA Templates, PLOS ONE 11, e0156478.

2. Heap, J. T., Pennington, O. J., Cartman, S. T., and Minton, N. P. (2009) A modular system for Clostridium shuttle plasmids, J. Microbiol. Methods 78, 79-85.

3. Topp, S., Reynoso, C. M. K., Seeliger, J. C., Goldlust, I. S., Desai, S. K., Murat, D., Shen, A., Puri, A. W., Komeili, A., Bertozzi, C. R., Scott, J. R., and Gallivan, J. P. (2010) Synthetic Riboswitches That Induce Gene Expression in Diverse Bacterial Species, Appl. Environ. Microbiol. 76, 7881.

4. Rao, G., Lee, J. K., and Zhao, H. (2013) Directed evolution of phloroglucinol synthase PhID with increased stability for phloroglucinol production, Appl. Microbiol. Biotechnol. 97, 5861-5867.

5. Denby, C. M., Li, R. A., Vu, V. T., Costello, Z., Lin, W., Chan, L. J. G., Williams, J., Donaldson, B., Bamforth, C. W., Petzold, C. J., Scheller, H. V., Martin, H. G., and Keasling, J. D. (2018) Industrial brewing yeast engineered for the production of primary flavor determinants in hopped beer, Nat. Commun. 9, 965.

6. Denaro, T., Chelgren, S., Lang, J., and Strobel, E. (2006) DNA Isolation of microbial contaminants in aviation turbine fuel via tradtional polymerase chain reaction (PCR) and direct PCR. AFRL-PRWP-TR-2006-2049. https://apps.dtic.mil/dtic/tr/fulltext/u2/a446701.pdf

7. Brophy, J. A. N., Triassi, A. J., Adams, B. L., Renberg, R. L., Stratis-Cullum, D. N., Grossman, A. D., and Voigt, C. A. (2018) Engineered integrative and conjugative elements for efficient and inducible DNA transfer to undomesticated bacteria, Nat. Microbiol. 3, 1043-1053.

8. Wiesenborn, D. P., Rudolph, F. B., and Papoutsakis, E. T. (1988) Thiolase from Clostridium acetobutylicum ATCC 824 and Its Role in the Synthesis of Acids and Solvents, Appl. Environ. Microbiol. 54, 2717-2722.

9. Hirsch, A., and Grinsted, E. (1954) 543. Methods for the growth and enumeration of anaerobic spore-formers from cheese, with observations on the effect of nisin, J. Dairy Res. 21, 101-110.

10. Zha, W., Rubin-Pitel, S. B., and Zhao, H. (2006) Characterization of the Substrate Specificity of PhID, a Type III Polyketide Synthase from Pseudomonas fluorescens, J. Biol. Chem. 281, 3203632047.

11. Silverman, A. D., Kelley-Loughnane, N., Lucks, J. B., and Jewett, M. C. (2019) Deconstructing CellFree Extract Preparation for in Vitro Activation of Transcriptional Genetic Circuitry, ACS Synth. Biol. 8, 403-414.

12. Kidarsa, T. A., Goebel, N. C., Zabriskie, T. M., and Loper, J. E. (2011) Phloroglucinol mediates cross-talk between the pyoluteorin and 2,4-diacetylphloroglucinol biosynthetic pathways in Pseudomonas fluorescens Pf-5, Mol. Microbiol. 81, 395-414.

13. McSpadden Gardener, B. B., Mavrodi, D. V., Thomashow, L. S., and Weller, D. M. (2001) A Rapid Polymerase Chain Reaction-Based Assay Characterizing Rhizosphere Populations of 2,4Diacetylphloroglucinol-Producing Bacteria, Phytopathology 91, 44-54.

14. Achkar, J., Xian, M., Zhao, H., and Frost, J. W. (2005) Biosynthesis of phloroglucinol, J. Am. Chem. Soc. 127, 5332-5333.

15. Pédelacq, J.-D., Cabantous, S., Tran, T., Terwilliger, T. C., and Waldo, G. S. (2006) Engineering and characterization of a superfolder green fluorescent protein, Nat. Biotechnol. 24, 79-88. 